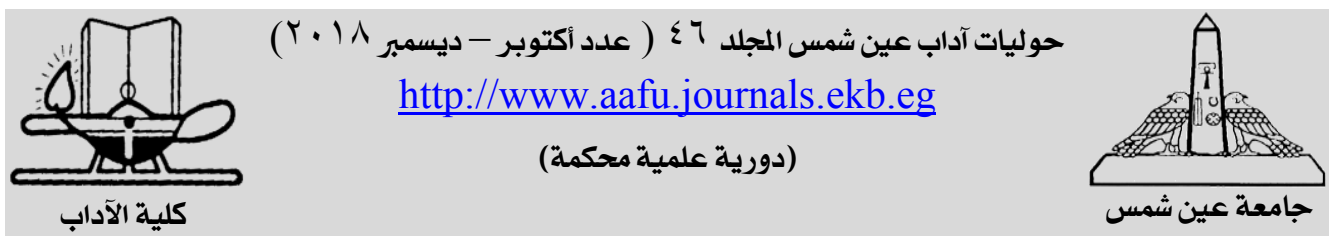

\title{
واو الفاصلة جواب التقابل
}

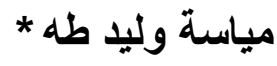

كلية التربية للعلوم الانسانية (ابن رشد) /جامعة بغداد

رصد البحث معنى جديدا تضمنته الفاصلة القرآنية بوصفها تعقيبا، وهو تعقيب يرى إنى فيه إفهام جديد لمعان في الآية، وهو ضابط يحتاج إلى ان تكون الفاصلة جملة مستقلة تؤدي

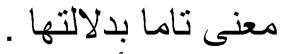

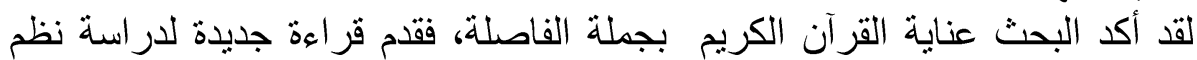

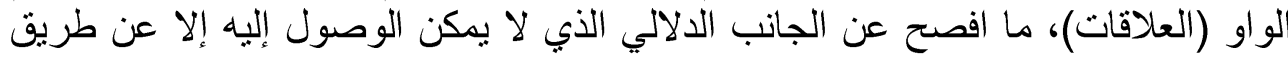

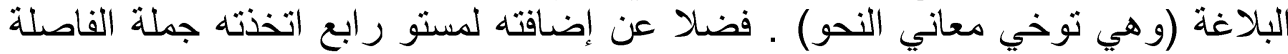

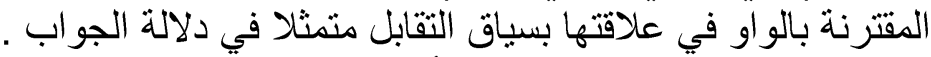

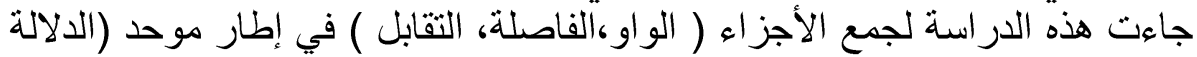

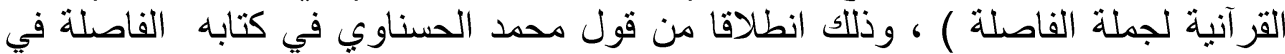

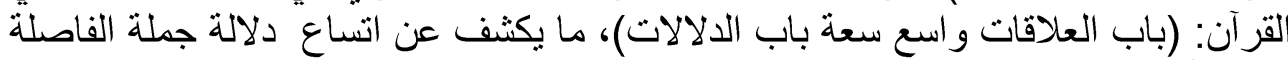

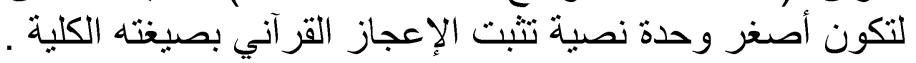

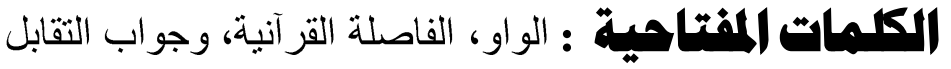


شكلت الفاصلة القر آنبة ظاهرة أسلوبية، تمبزت بها لغة القابة القرآن الكريم، فهي من

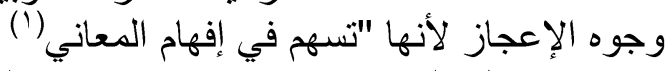

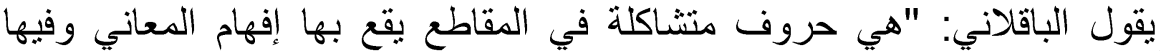

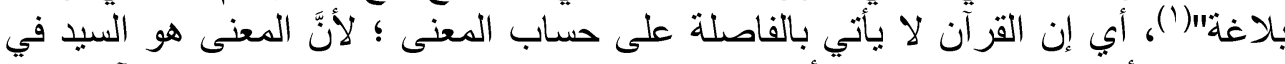

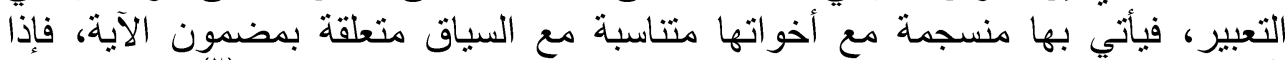

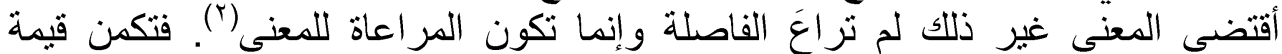

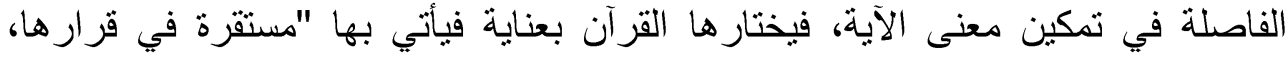

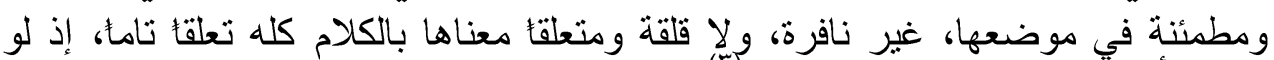

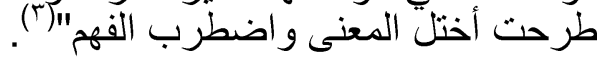

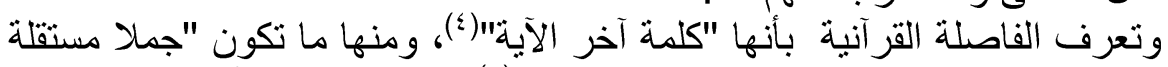

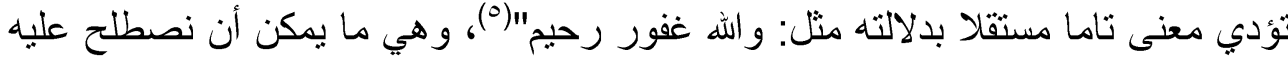

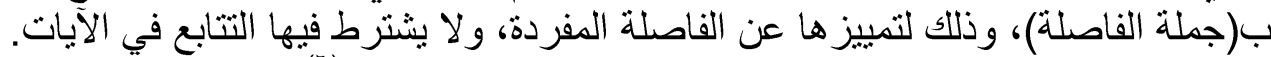

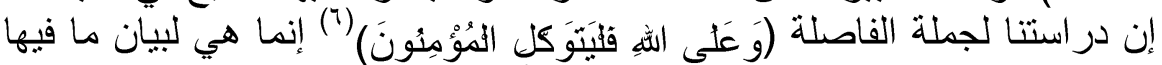

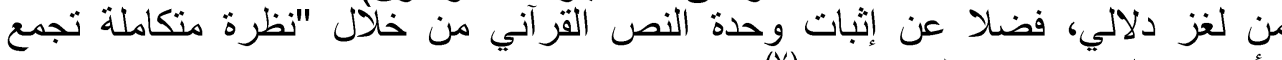

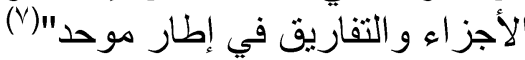
ثانيا: الواو بين العطف و الاستئناف

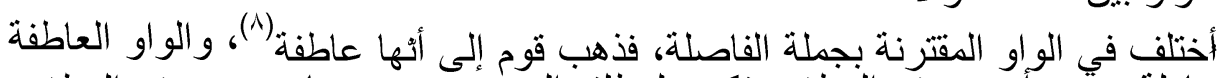

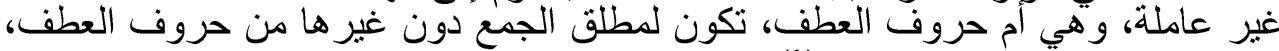
تفيد التشريك في الحكم و الاعراب(ج).

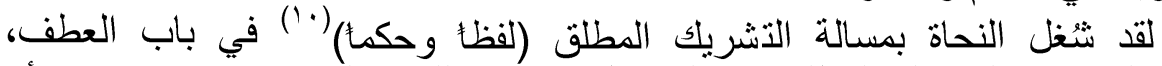

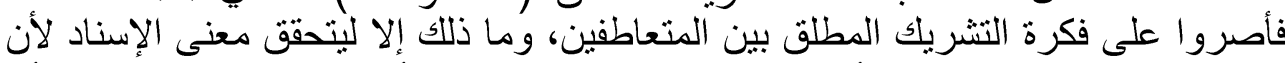

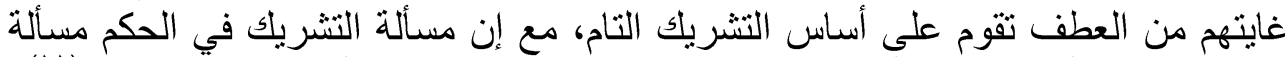

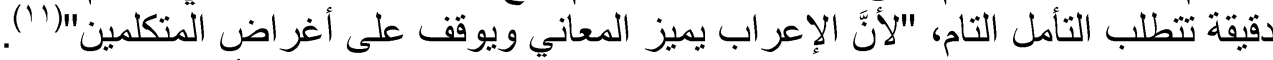

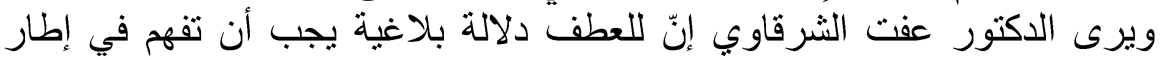

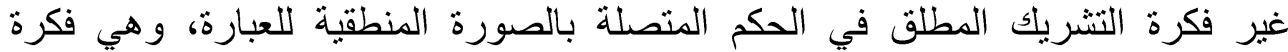

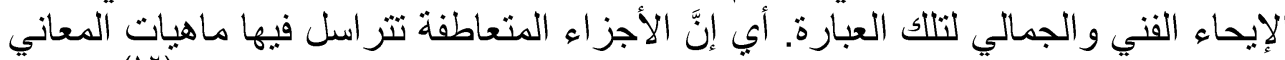

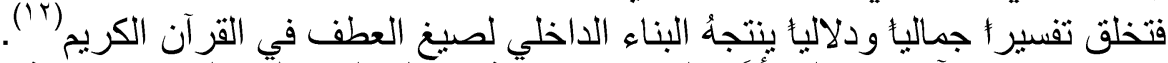

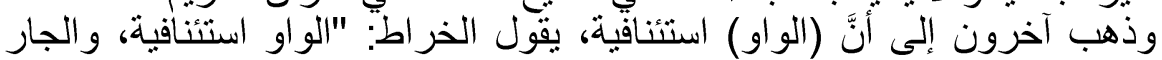

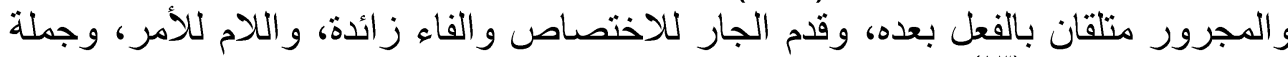

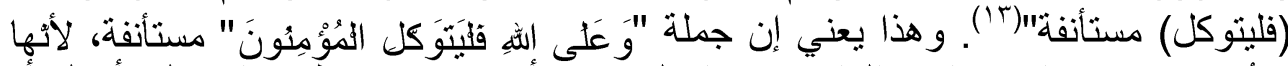

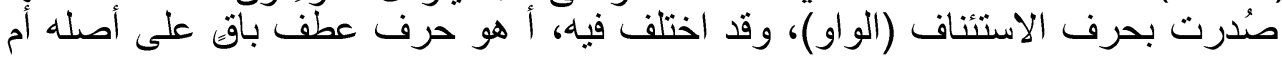
حرف عطف أصلاد، ولكنه خرج عنه الإنى الاستنئناف؟

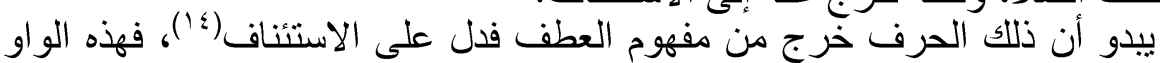

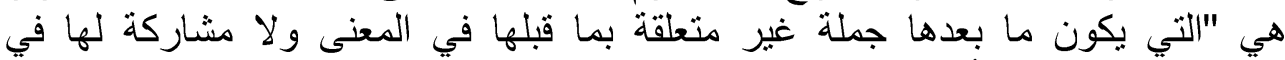

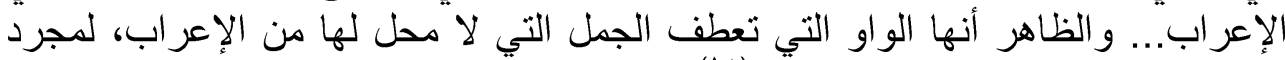
الربط، وإنما سميت واو الاستئناف"(10.). ويسمى هذا النوع من الاستئناف بالاستئناف الإن

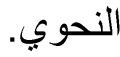


لقد تتبه ابن هشام إلى وجود نوع آخر من الاستنتاف، وهو الاستنتاف البياني فعبر

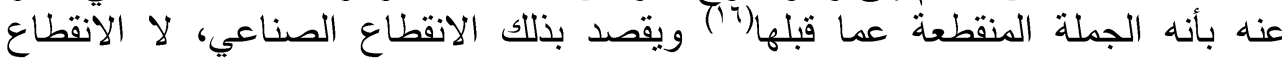
المعنوي ف"الانقطاع الإعرابي لا يستلزم إنقطاعا في المعنى، والإنقطاع المعنوي لا يستلزم

هذه حال الواو سين العطف والاستئنافـ في الآيات التي جاءت بها جملة الفاصلة

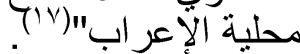

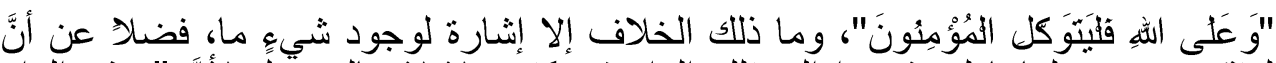

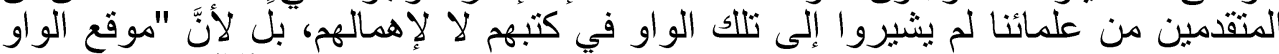

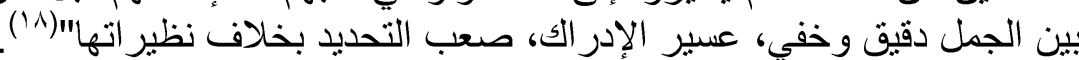

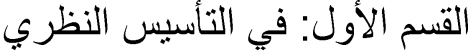

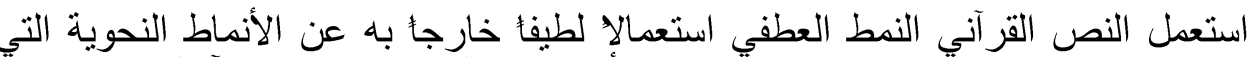

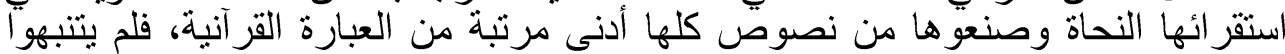
لتفرد القر آن المطلق في البلاغة و البيان.

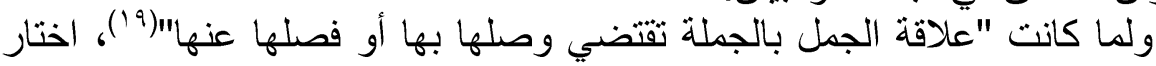

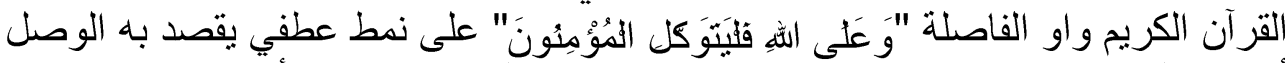

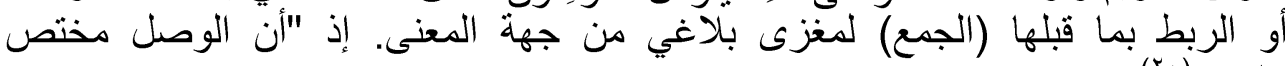

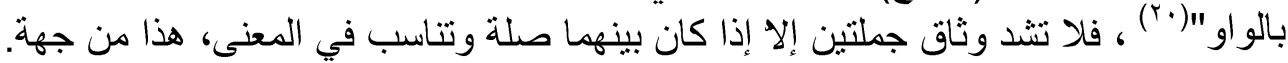

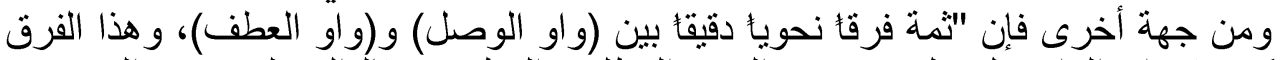

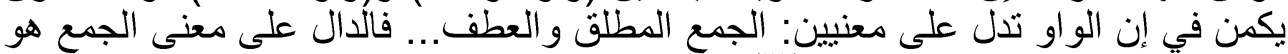

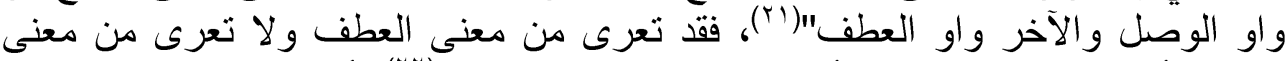

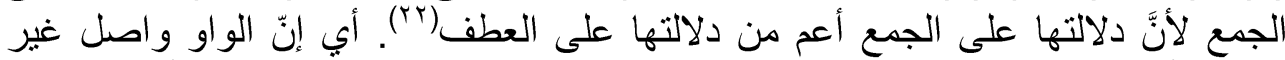

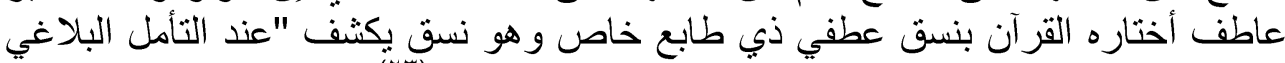

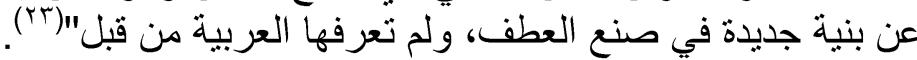
لقد وقع النحاة في "بعض المشكلات الاسلوبية التي واجهتهم في العبار ات القرآناتية

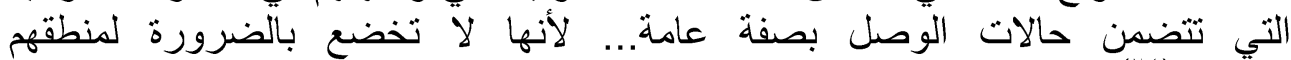

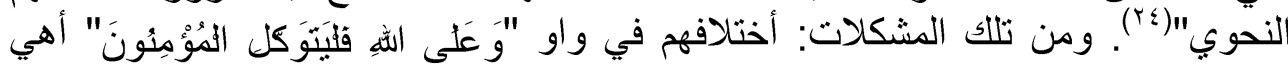

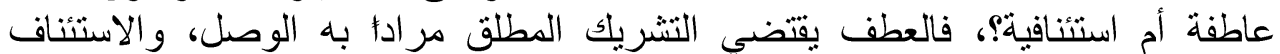

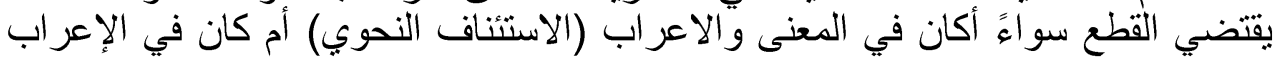
دون المعنى (الاستئناف البياني).

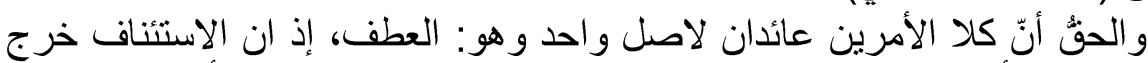

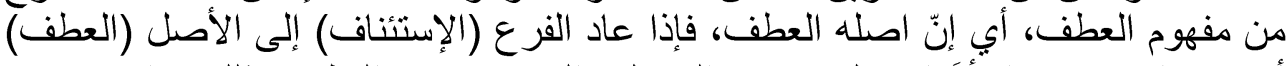

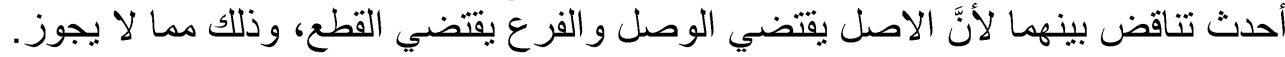

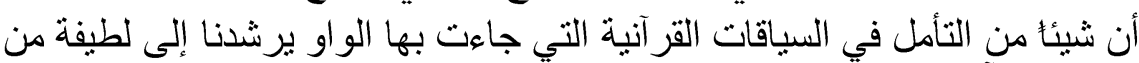

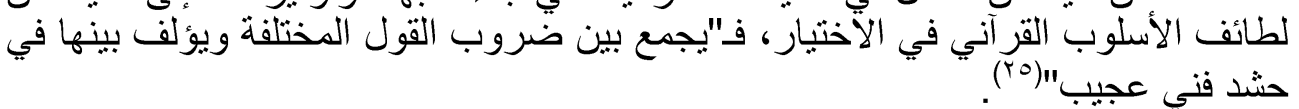

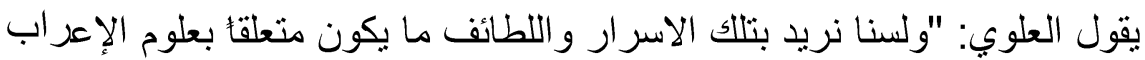

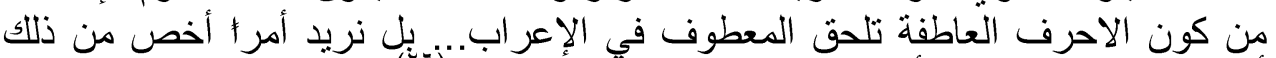

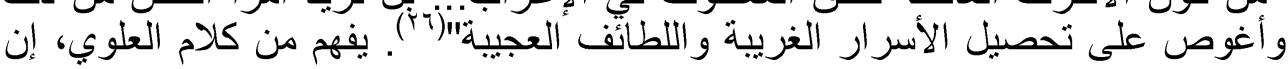

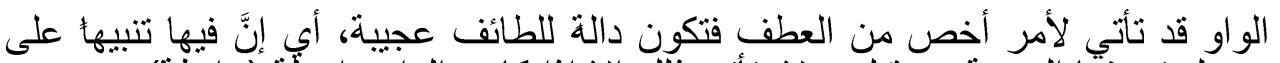

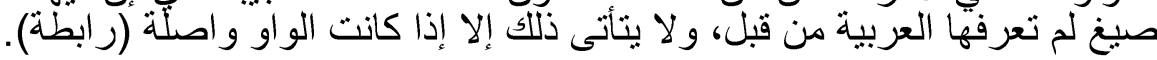




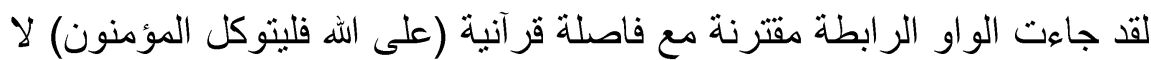

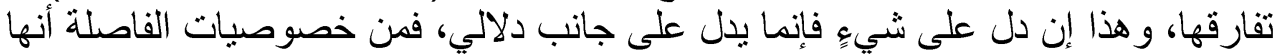

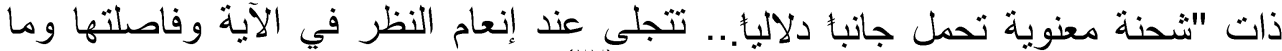

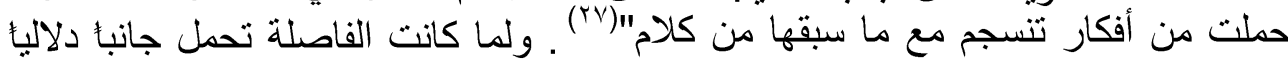

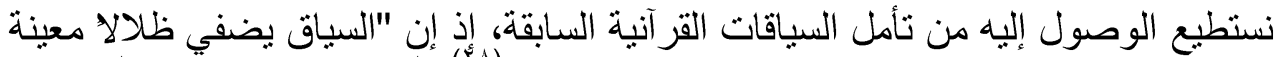

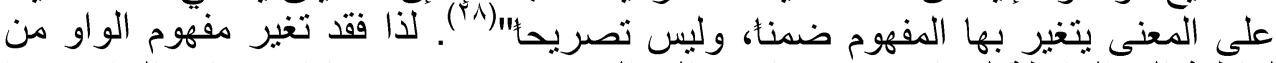
العاطفة إلى الر ابطة لجواب، وهو ما تتبه إليه البلاغيون حين خصوا الاستئناف البياني "بما

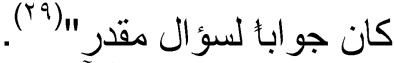

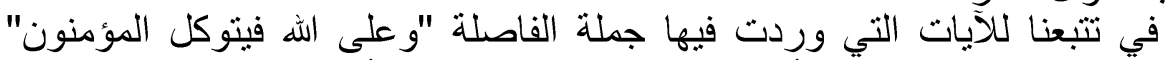

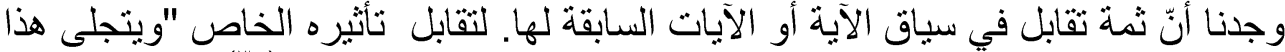

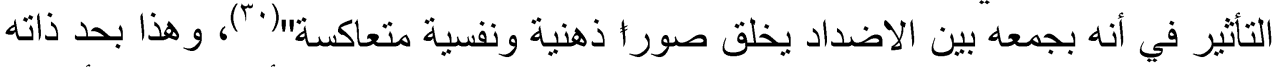

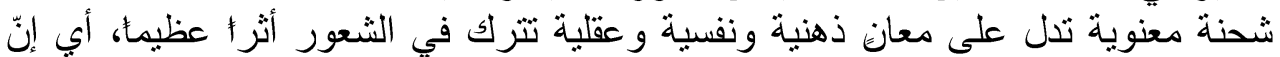

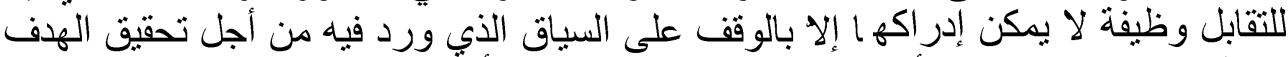

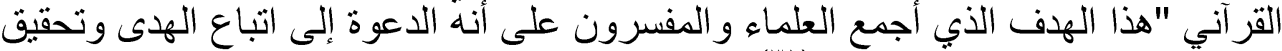

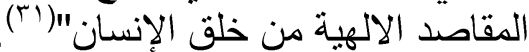

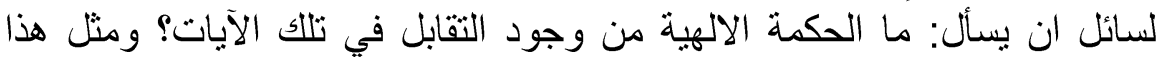

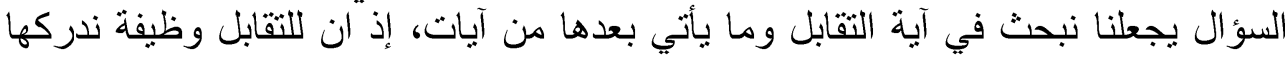

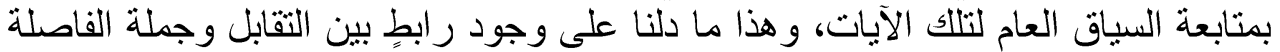

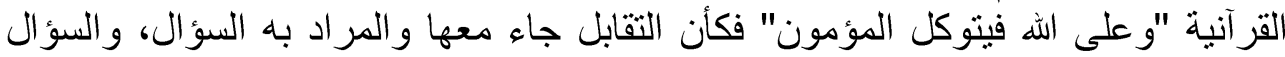

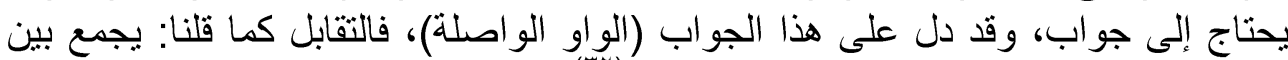

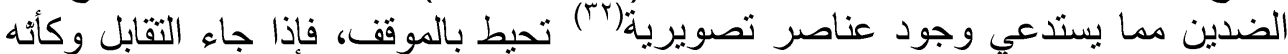
سؤال بأتيه الجواب من رب العزة وفيه أمر منه سبحانه باختيار أحد الضدين استقر ذلك في في التهاب

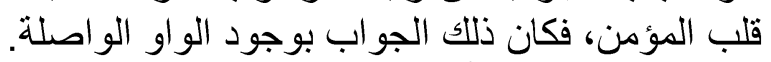

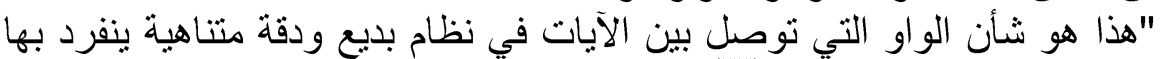

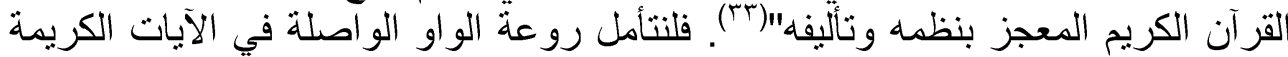

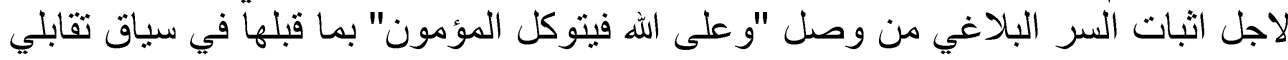

\section{القشم الثاني: في التكريس الإجرائي}

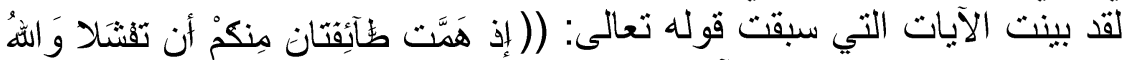

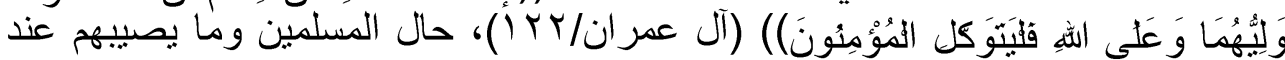

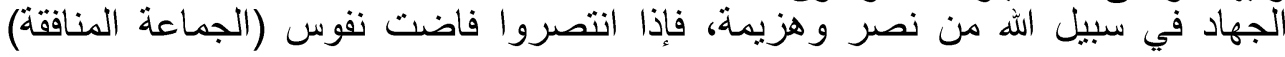

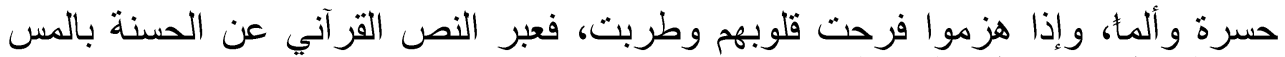

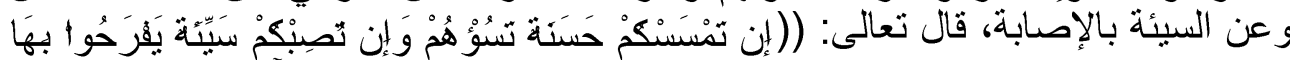

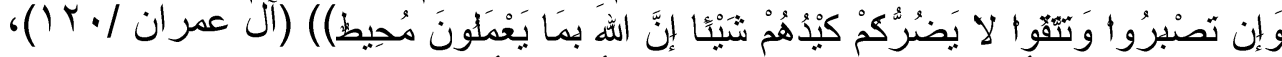

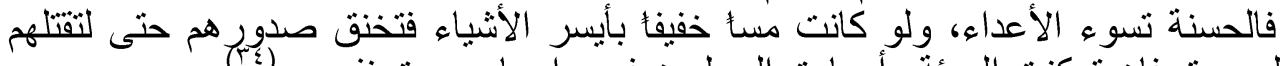

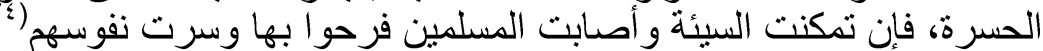

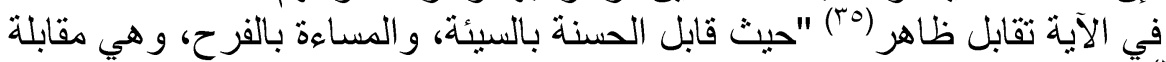

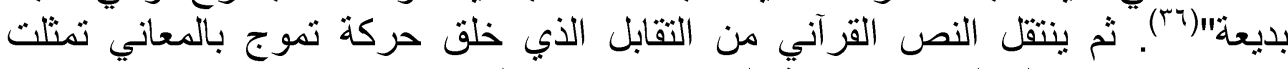

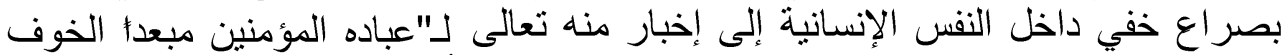

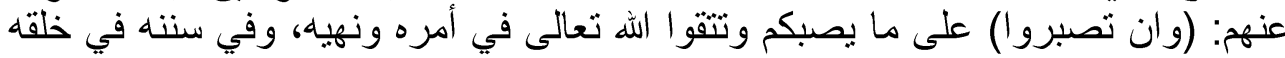
لا يضركم كيدهم شيئٌ، لأنّ الهه تعالى وليكم مطلع على تحركاتهم وسائر تصرفاتهم 


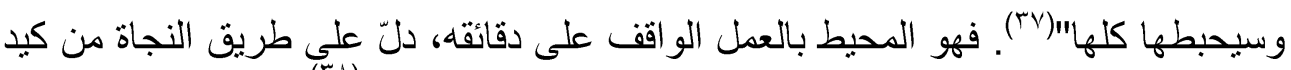

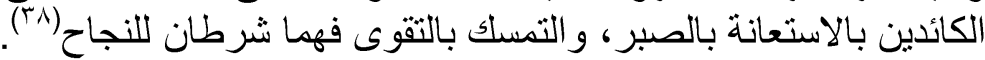

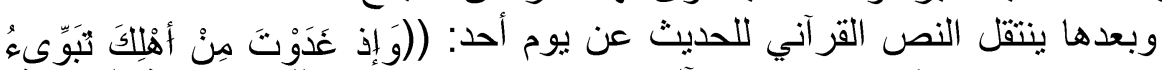

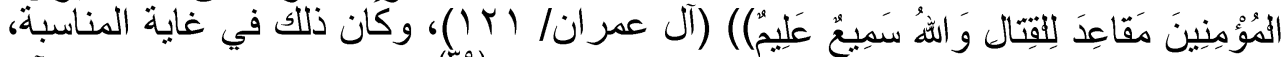

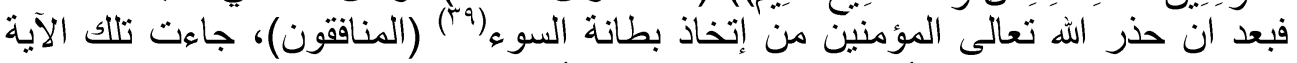

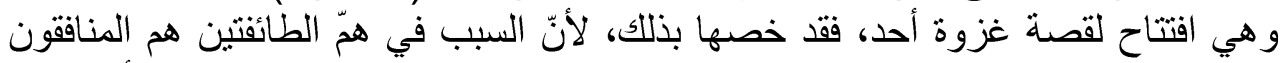

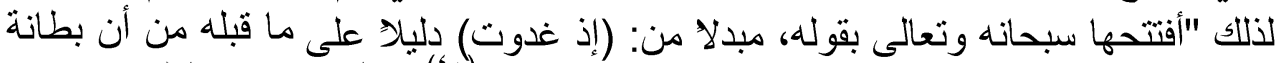

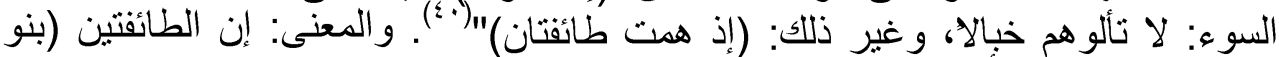

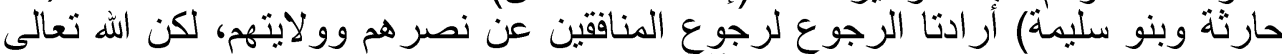

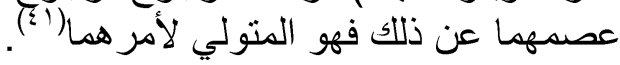

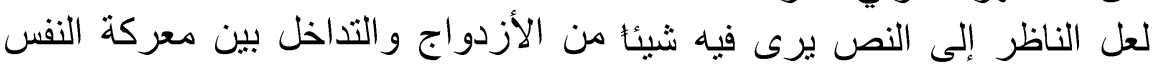

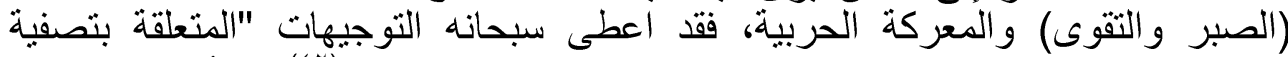

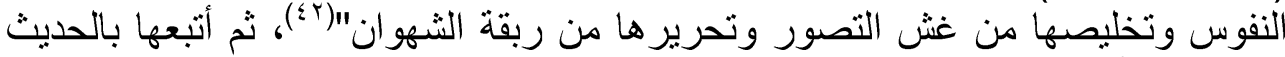

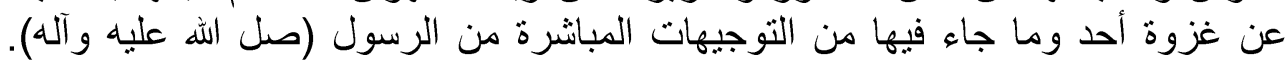

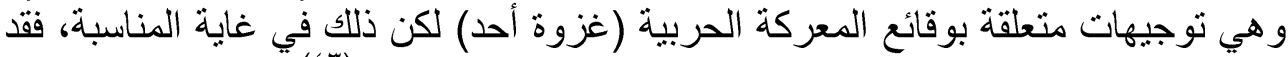

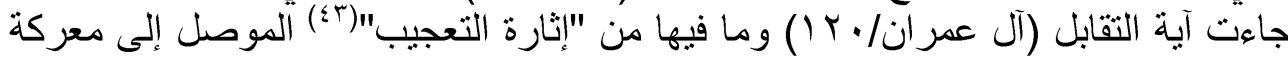

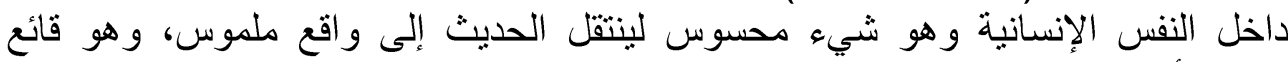
معركة أحد وما يصيب الإنيانة وهلمين فيهاء و هكذا كثفت لنا هذه الآيات فكرة (التوحيد و إثبات وحدانية الهه تعالى وإن الأمر

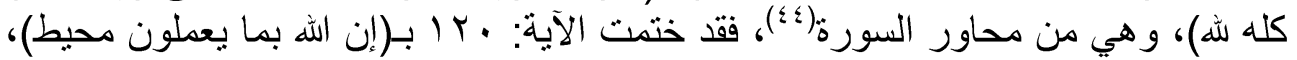

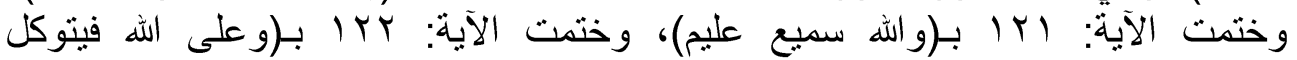

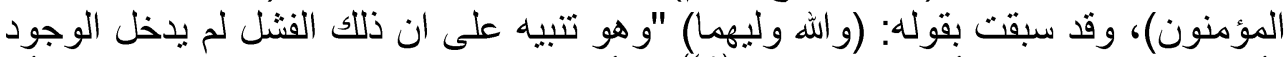

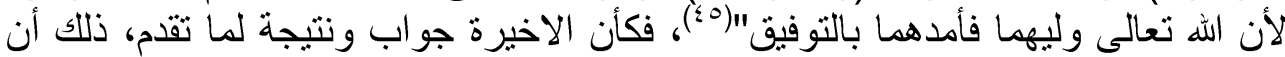

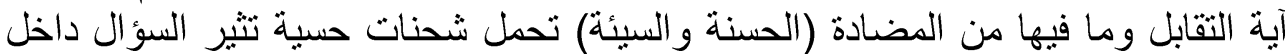

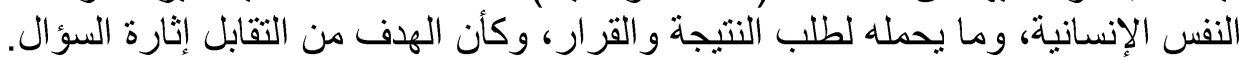

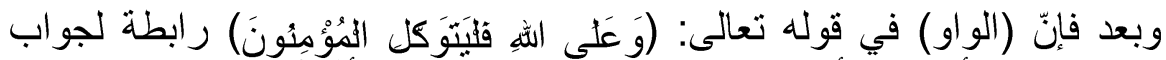

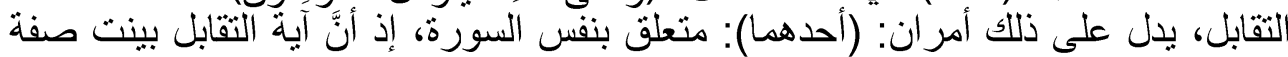

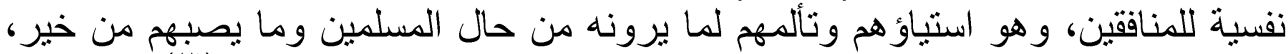

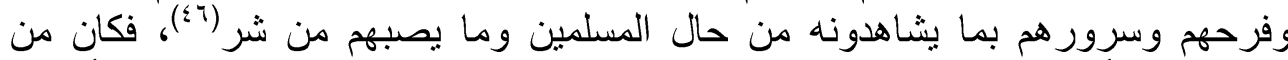
المناسب لها أن يكون الجو اب على صفة نفسية، و التوكل على الله يكون محله القلب، أي إنه

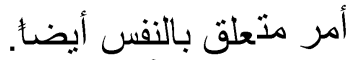

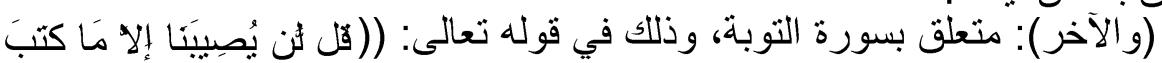

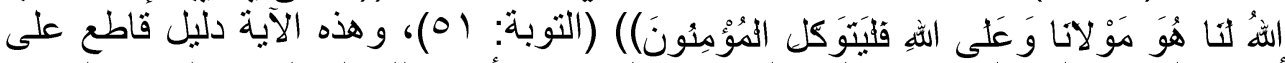

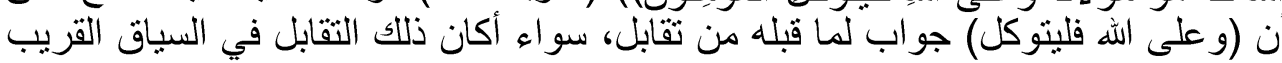

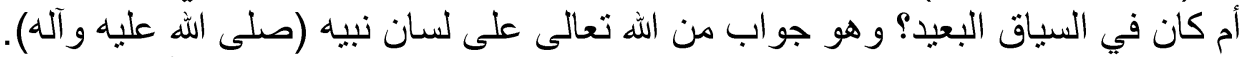

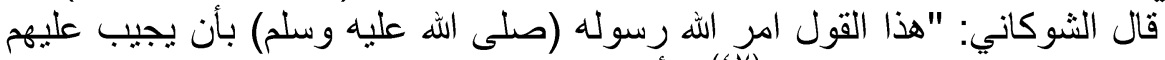

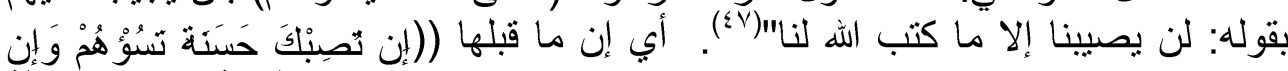

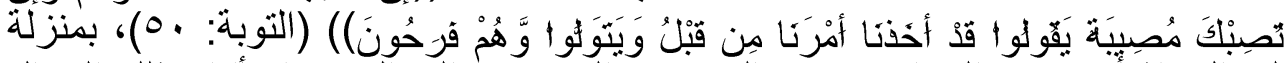

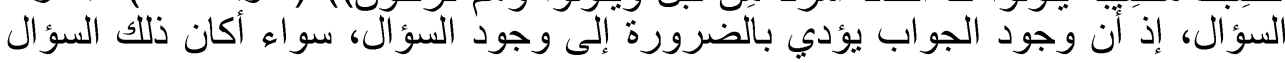




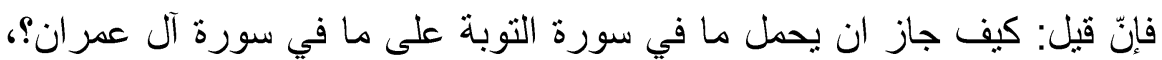

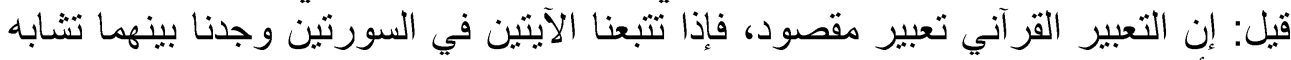

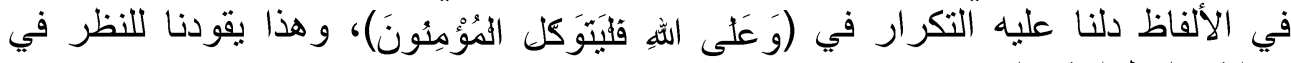
سو ابقهما ولو احقهما. - الكا. قال السيوطي: "فإن رأيت شيئًا مكرر| مأن حيث الظاهر، فأنظر في سوابقه

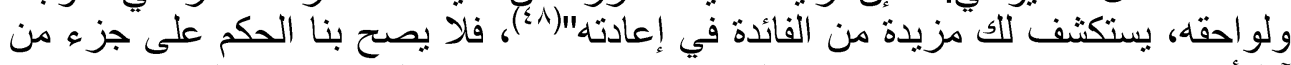

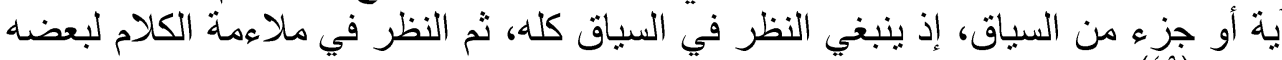

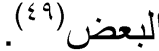

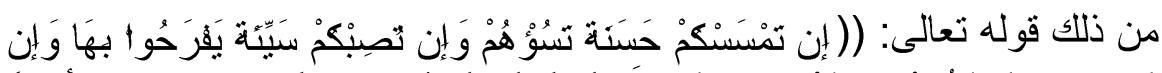

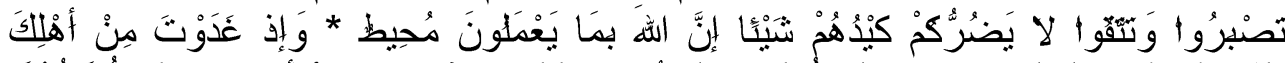

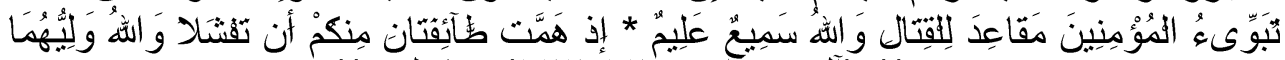

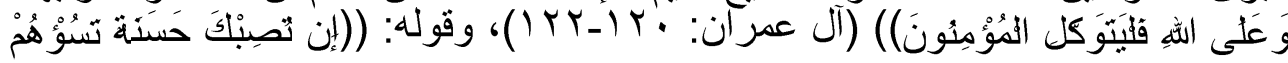

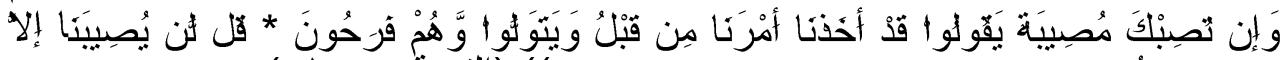

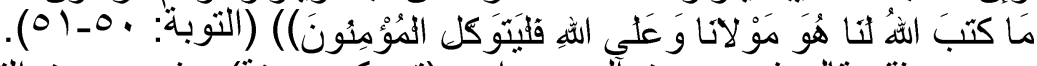

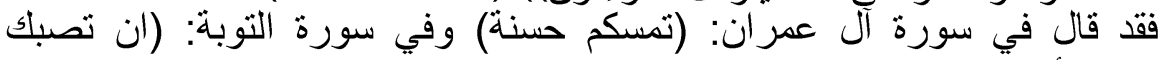

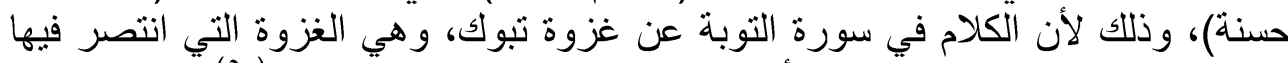

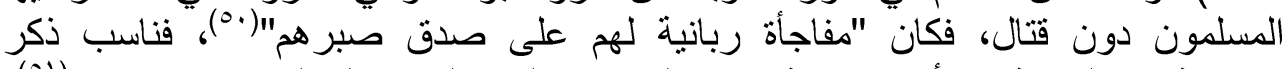

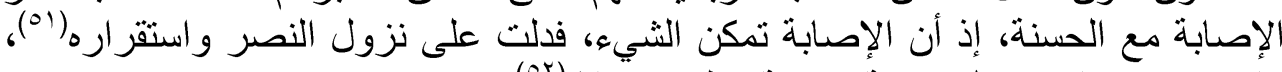

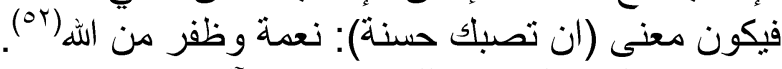

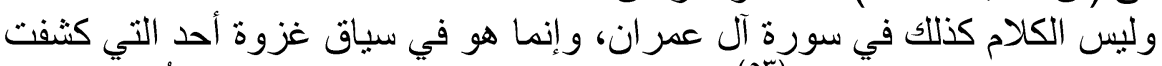

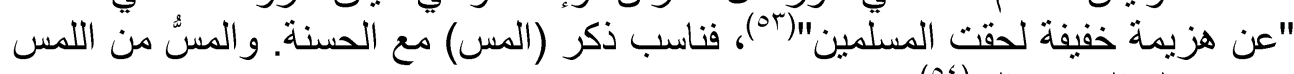

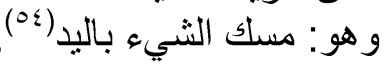

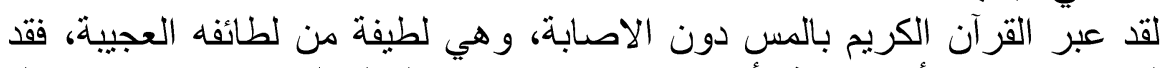

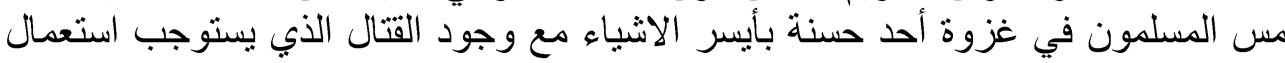

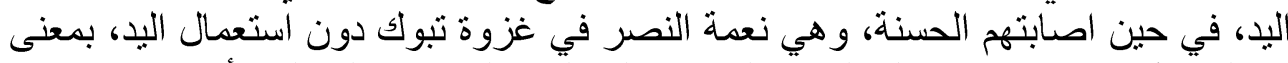

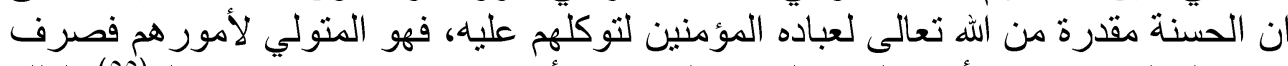

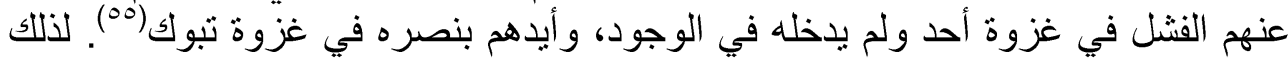

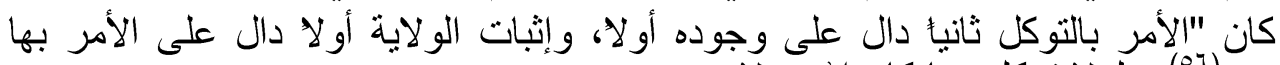

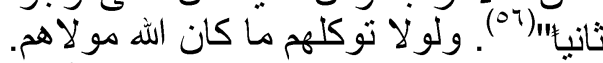
هذا من ناحية، ومن ناحية أخرى فإنّ السياق المقامي تتطلب استحضار الجملة

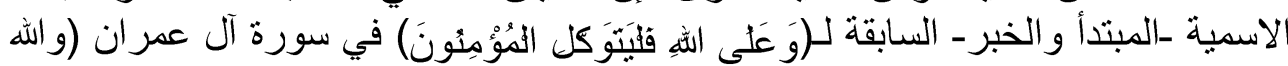

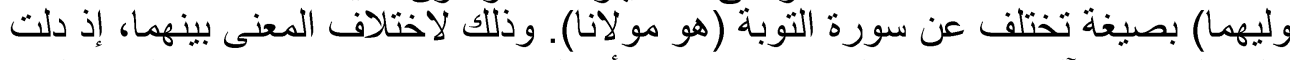

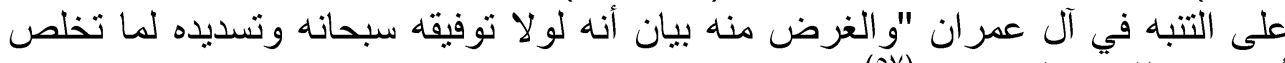

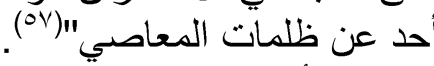

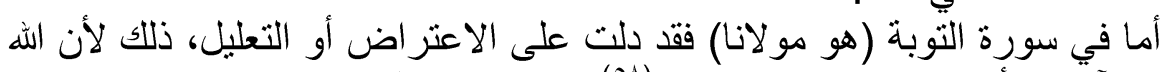

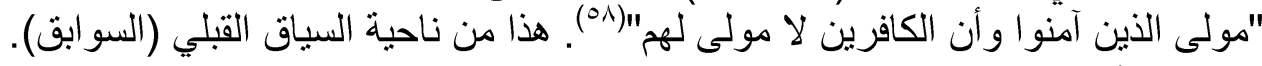

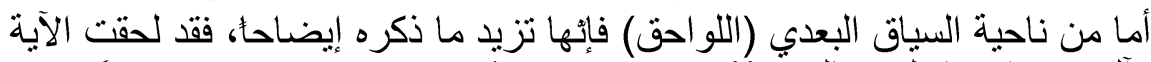

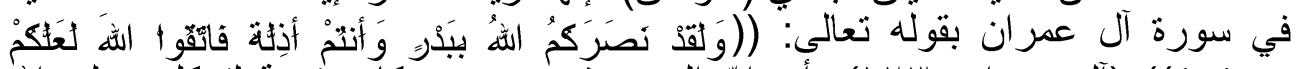

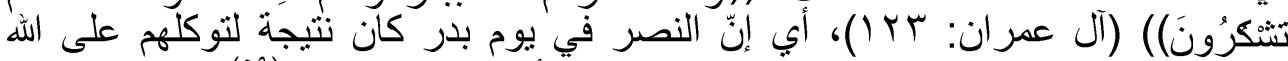

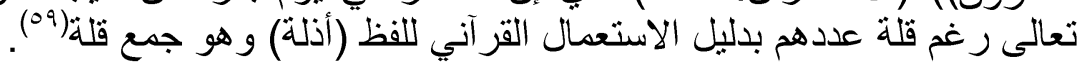


أما في سورة التوبة، فقد لحقت آية التوكل بقوله تعالى: ((لَّن هَلْ تَرَبَّصُونَ بنَا إلان

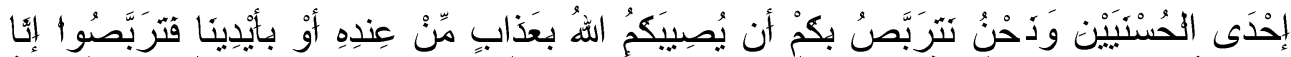

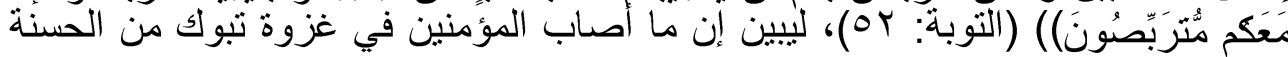

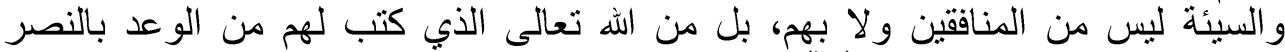
ومضاعفة الأجر على المصيبة(")، بدليل قوله سبحانه: (أحدى الحسنيين).

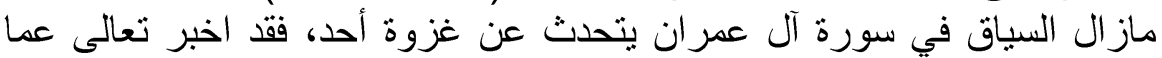

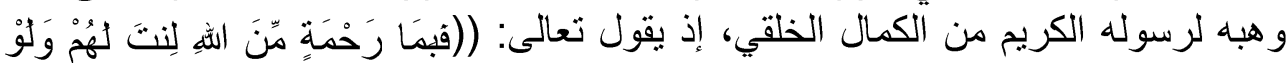

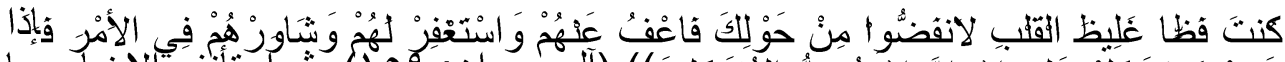

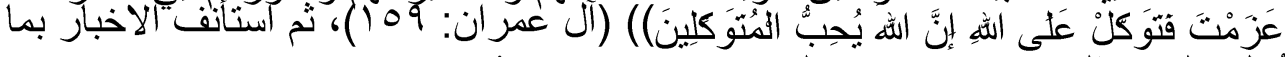

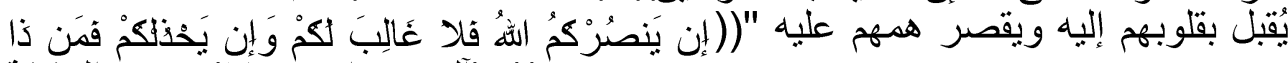

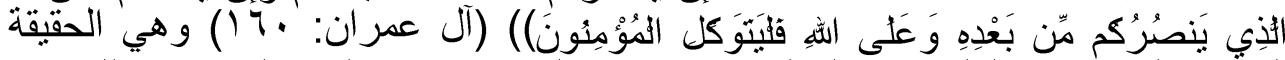

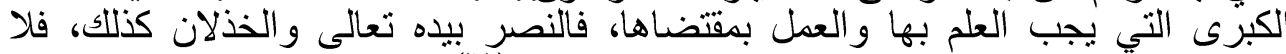

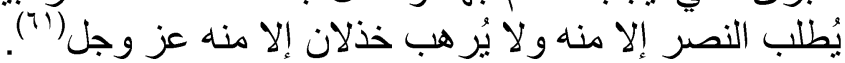

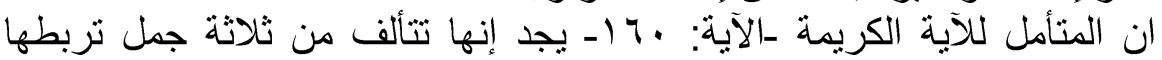
الواو. تضمنت الاولى والثانية شرطا جوابه في الفاء وما بعدها، فجاء قوله: (قَلا غَالِبَ)

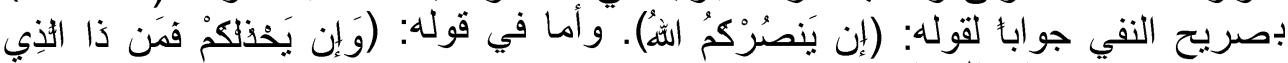

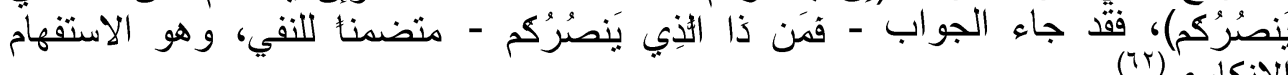
الانكاري(7r)

لقد رُبطت الجملتان الثرطيتان بالواو العاطفة، فهما مشتركتان في الحكم

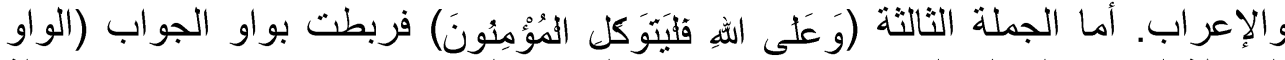

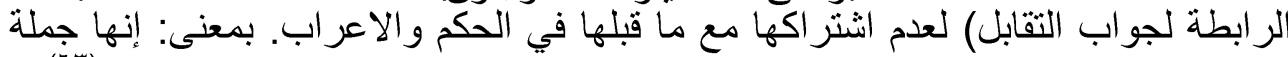

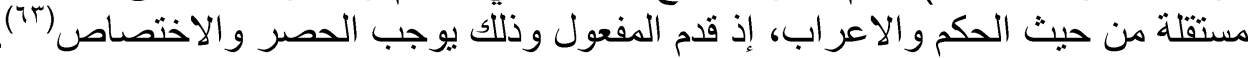

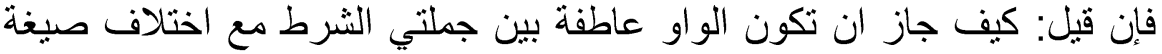

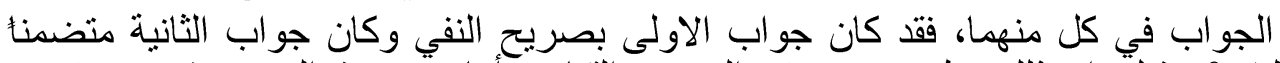

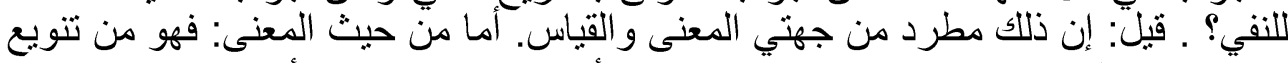

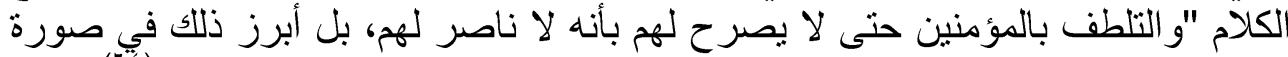

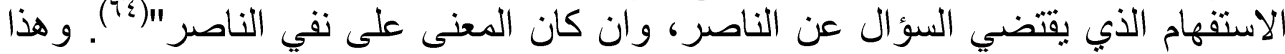

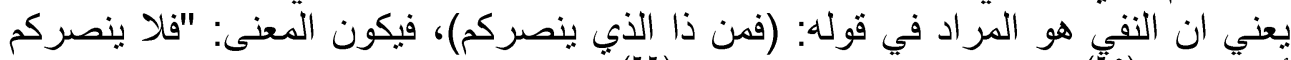

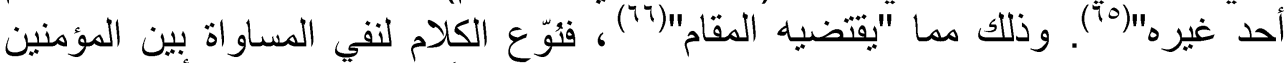

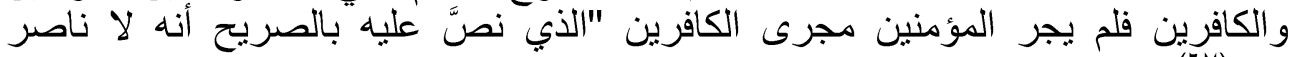

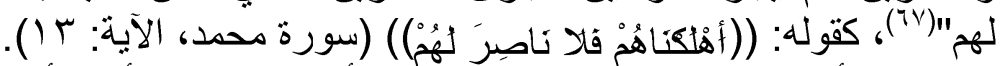

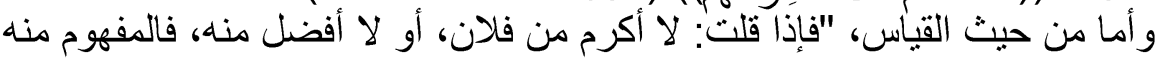

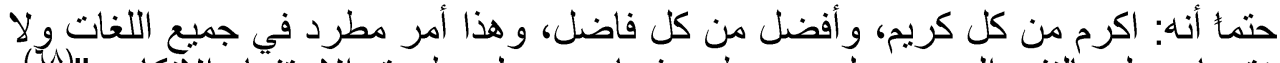

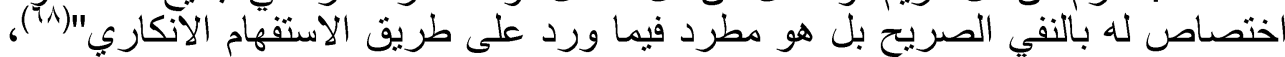

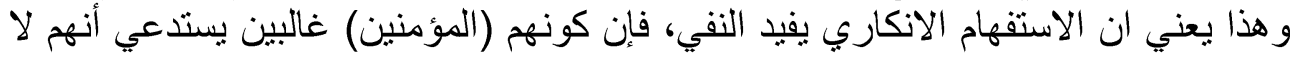

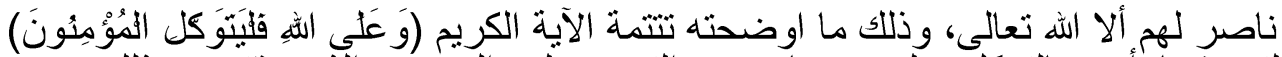

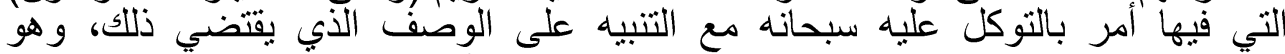

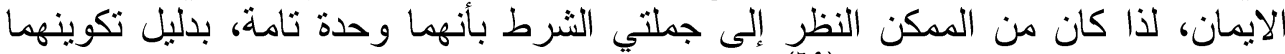

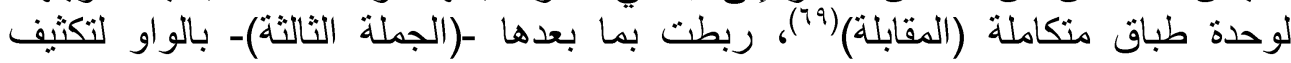




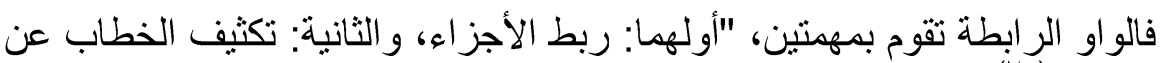

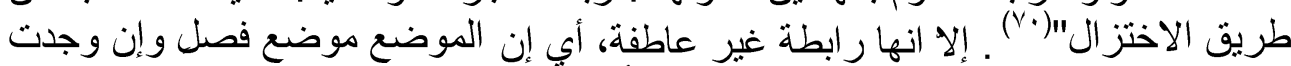

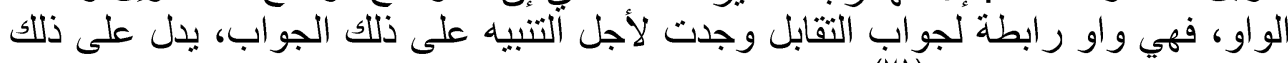

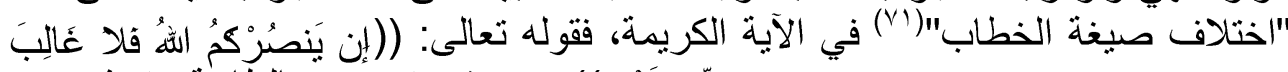

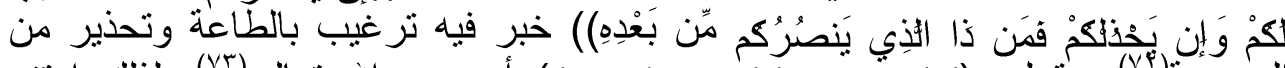

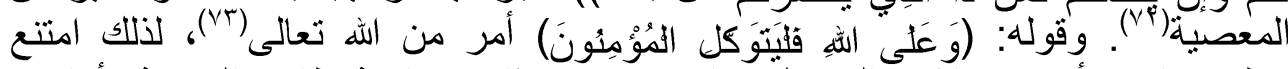

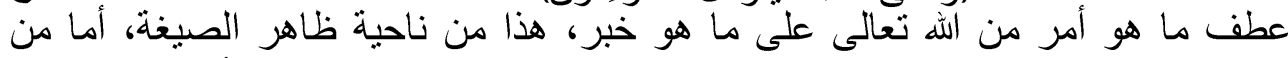

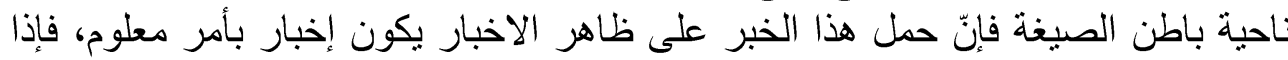

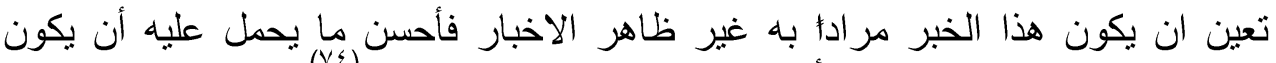

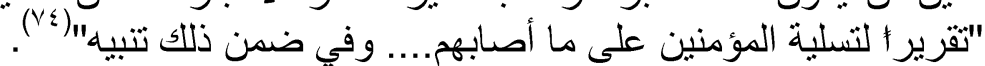

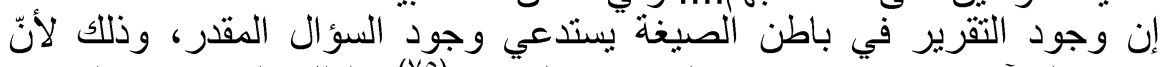

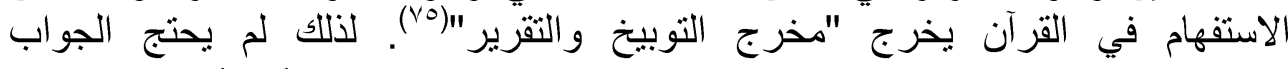

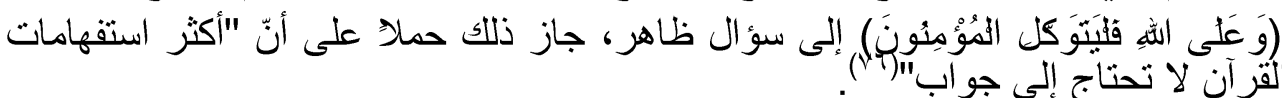

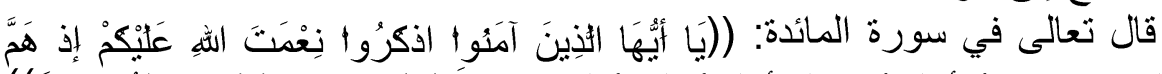

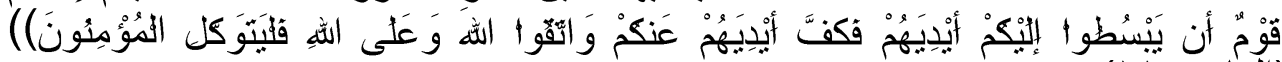

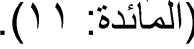

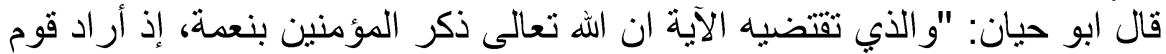

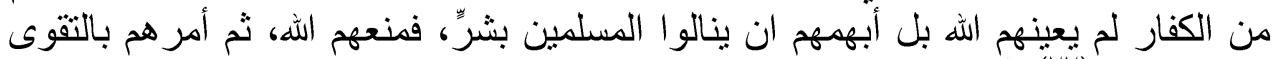

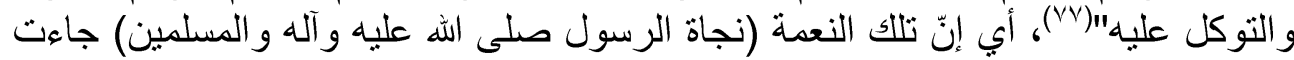

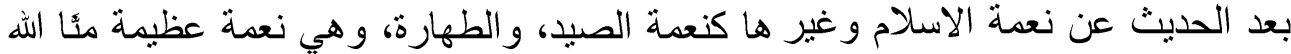

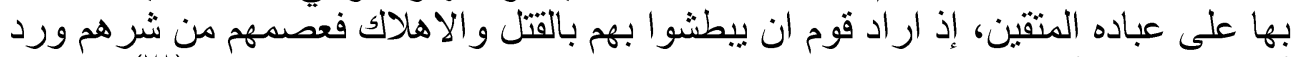

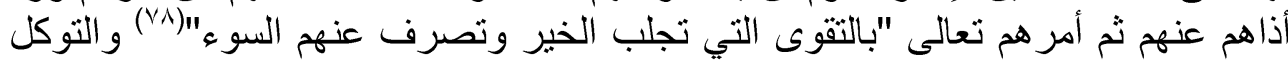
عليه و"هو: الوثوق به عند الملمات والاعتماد عليها في سائر الحالات، وهي مرتبة التهات سامية

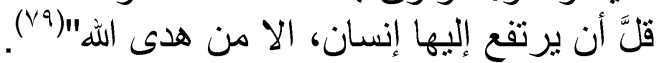

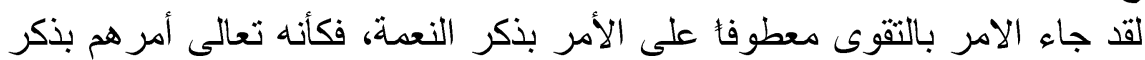

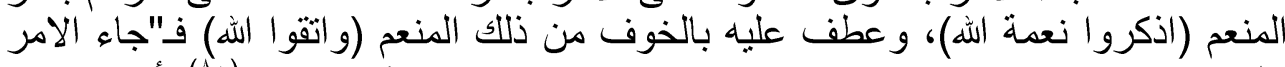

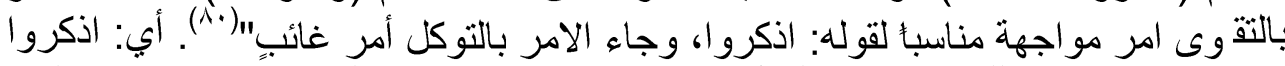

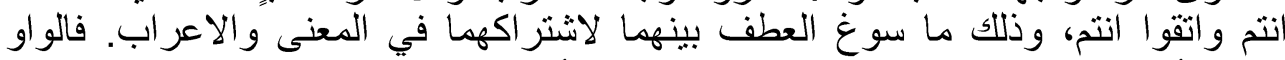

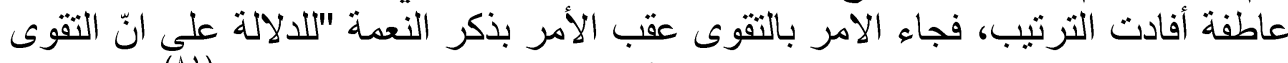

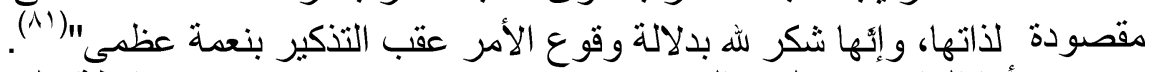

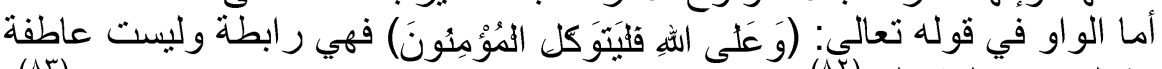

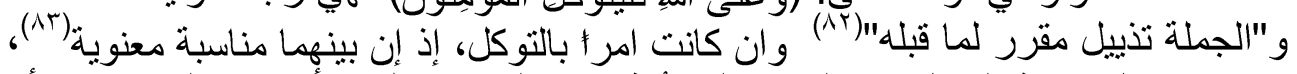

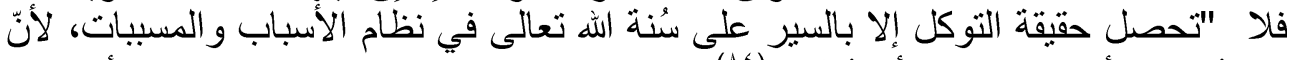

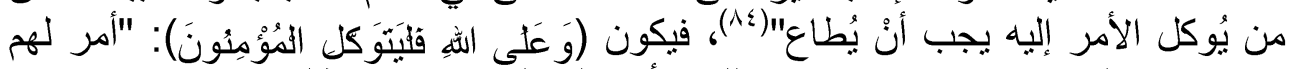

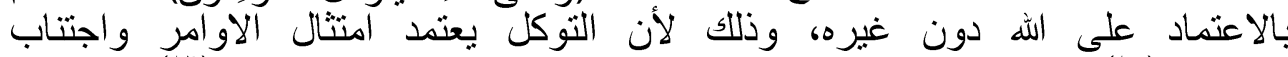

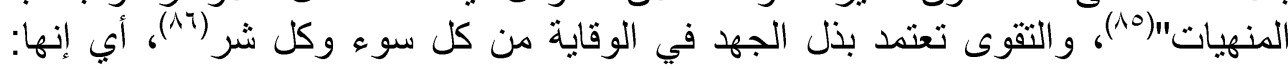

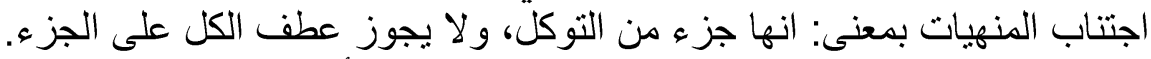

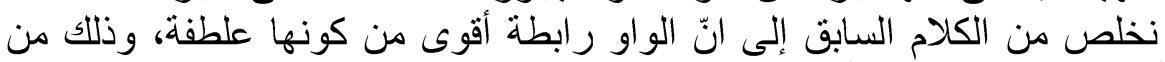

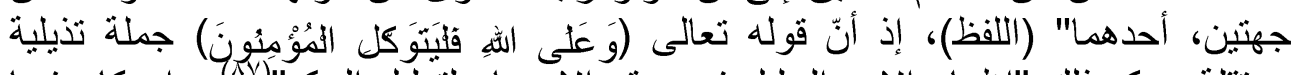

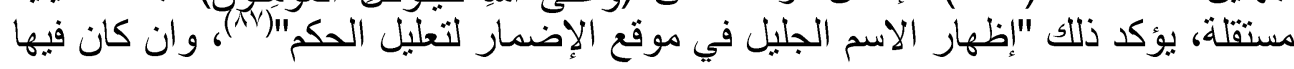


الامر بالتوكل الواقع بعد الامر بذكر النعمة والمعطوف عليه بأمر التقوى، وهو امر غائب

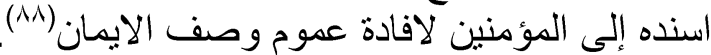

لقائل ان يقول: ان السبب في اسناد صيخة أمر الغائب (فليتوكل) إلى المؤمنين

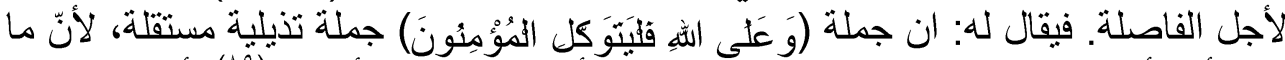

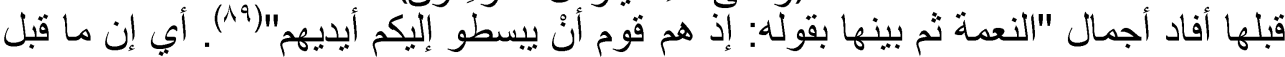

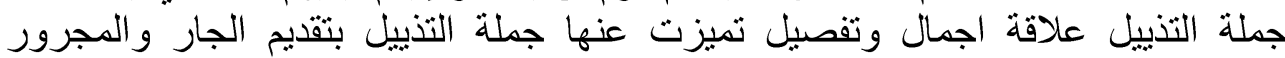

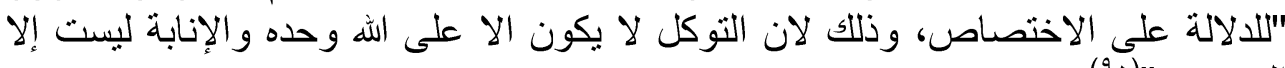

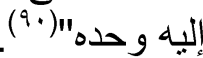

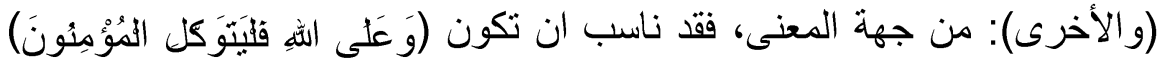

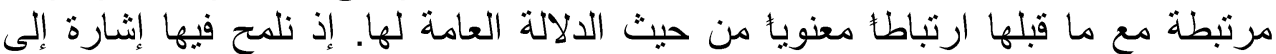

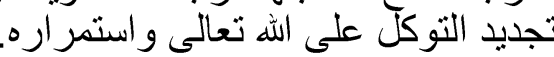

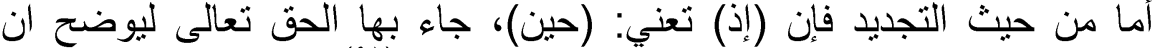

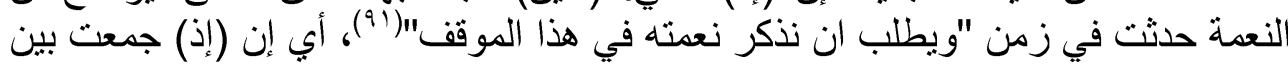

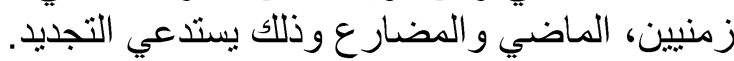

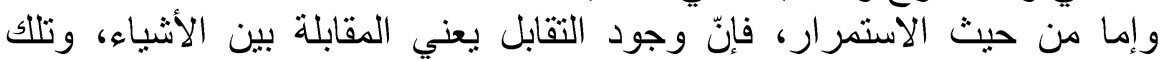
المقابلة تحتمل الأمرين: الجيد والسيء، وهما مستمر ان إلى قيام الساعة و وعلى المؤمنين ان يميزوا بينهما. أن التعبير القر آني تعبير فني مقصود له طرق عدة منها طريقة الصورة والحة والحركة،

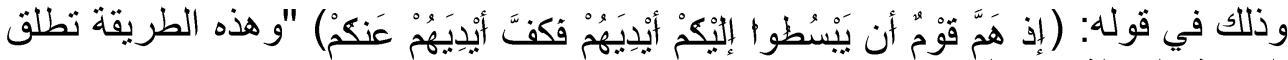

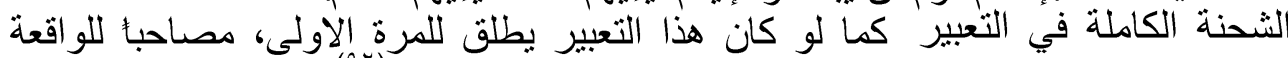

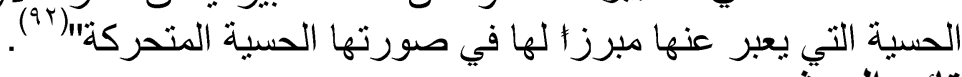
نتائج البحتي"

عالج البحث ثلاث ظو اهر أسلوبية يجمعها باب العلاقات، وقد خلص الى النتائج الآتية:

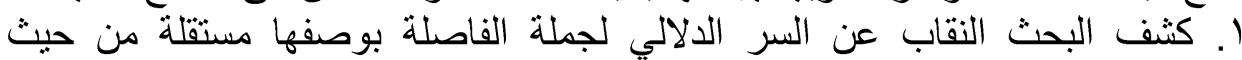

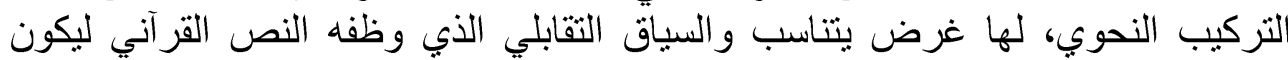
متضمنا لجانب بلاغي يمكن الوصول إلبه عن طريق علم البديع، ما يعمل على إلى إيراز

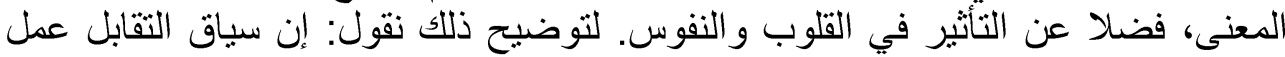

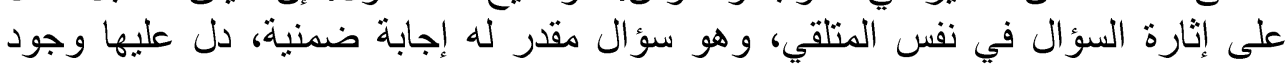

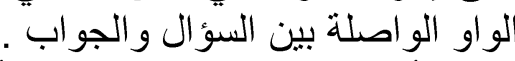

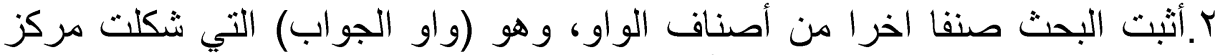

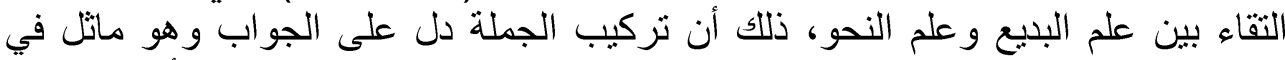

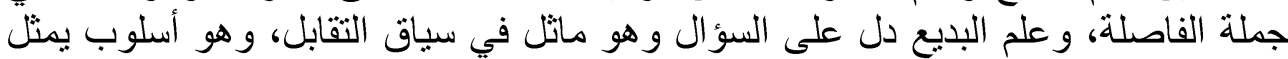
جمعا للالالة، إذ ارتبط الجانبان البلاغي و النحوي لتحقيق دلالة الجي الجواب، فلا يلان يمكن تصور

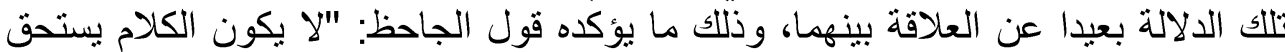

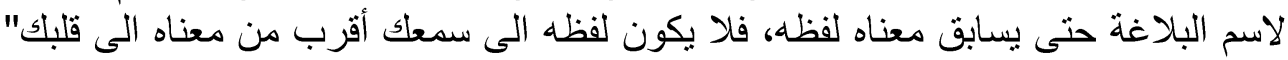

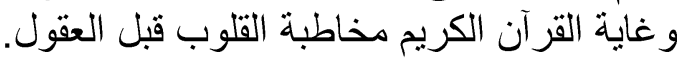

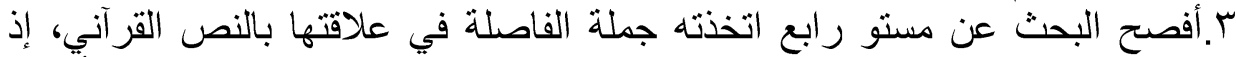

تجاوزت الآية والمقطع والسورة لتكون علاقة بنص كامل، وهي علاقة التهة تجمع الأجزاء و التفاريق في أصغر وحدة نصية (الجملة) يثبت بها الإعجاز القرة أني بصي بهته الكلية . 


\section{Abstract \\ F. Interval response mapping \\ By Mayassa W. Taha}

The present paper identified a new meaning for the Qura'nic explanatory "waw" which includes it as an explanation; it is an explanation which aims to propose a new understanding of meaning in the Qura'nic verses. It is a criterion that needs the explanatory "waw" to be an independent sentence that gives a complete semantic meaning.

The present paper stressed on the Holy Qura'n care of the explanatory "waw" sentence, thus it presented a new view of the "waw" systems study (relations) that reveal the semantic role which can notde reached only through eloquence (which means taking into consideration meanings of syntax). This is in addition to adding a fourth level that the explanatory "waw" sentence adopted in its relation with the correspondence context represented by the semantic reply.

Based on what Mohammed Al.Hasnawi says in his book The Explanatory in the Holy Qura'n (The gate of the relations is as wide as the gate of semantics), the present study came to combine the parts (the waw, the explanatory, the correspondence) in a unified frame (the semantic Qura'n of the explanatory sentence). It revealed the width of the semantic aspects of the explanatory sentence to be the smallest text unit which proves the comprehensive inimitability of the Holy Qura'n.

Key words: Correspondence reply, the Qura'nic explanatory waw, the waw.

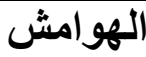

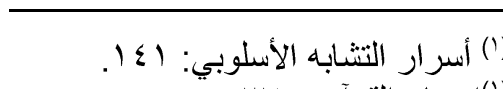

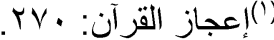

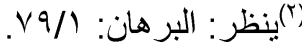

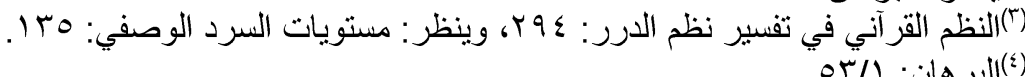

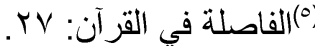

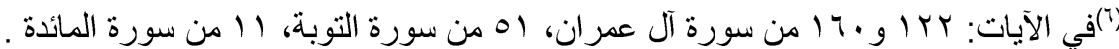

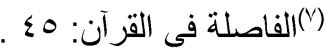

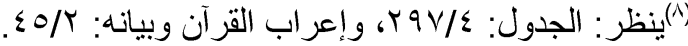$$
\text { (") }
$$

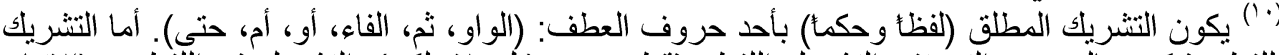

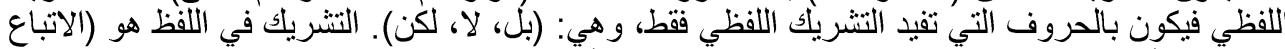

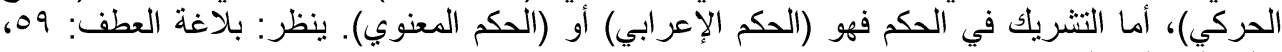

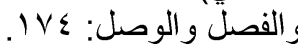

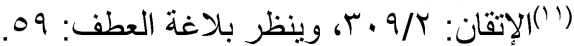

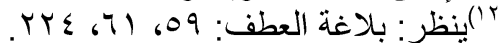

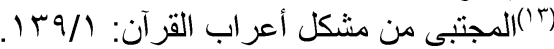
(') ('ينظر : الجمل التي لا محل لها: 97. 


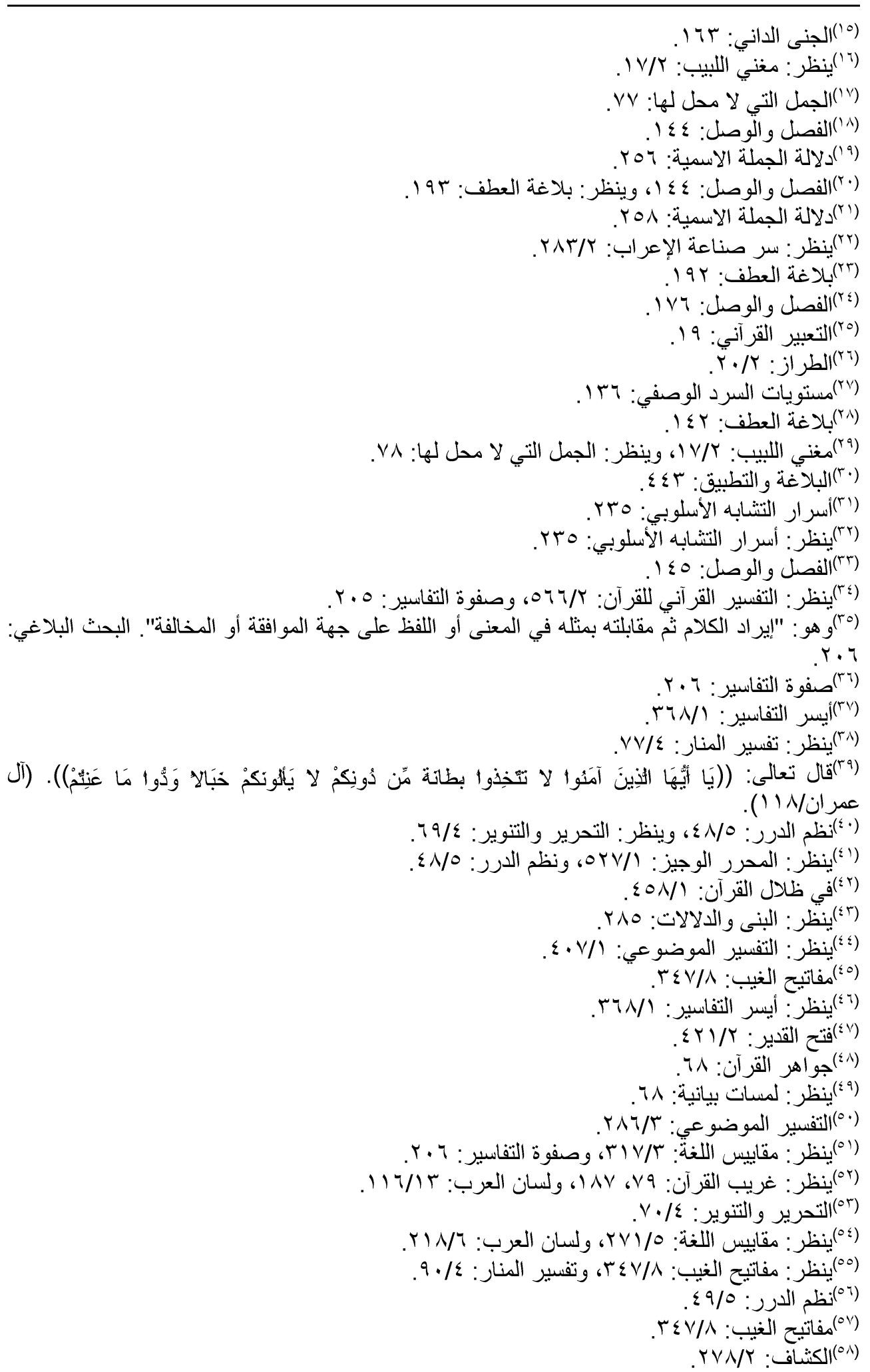




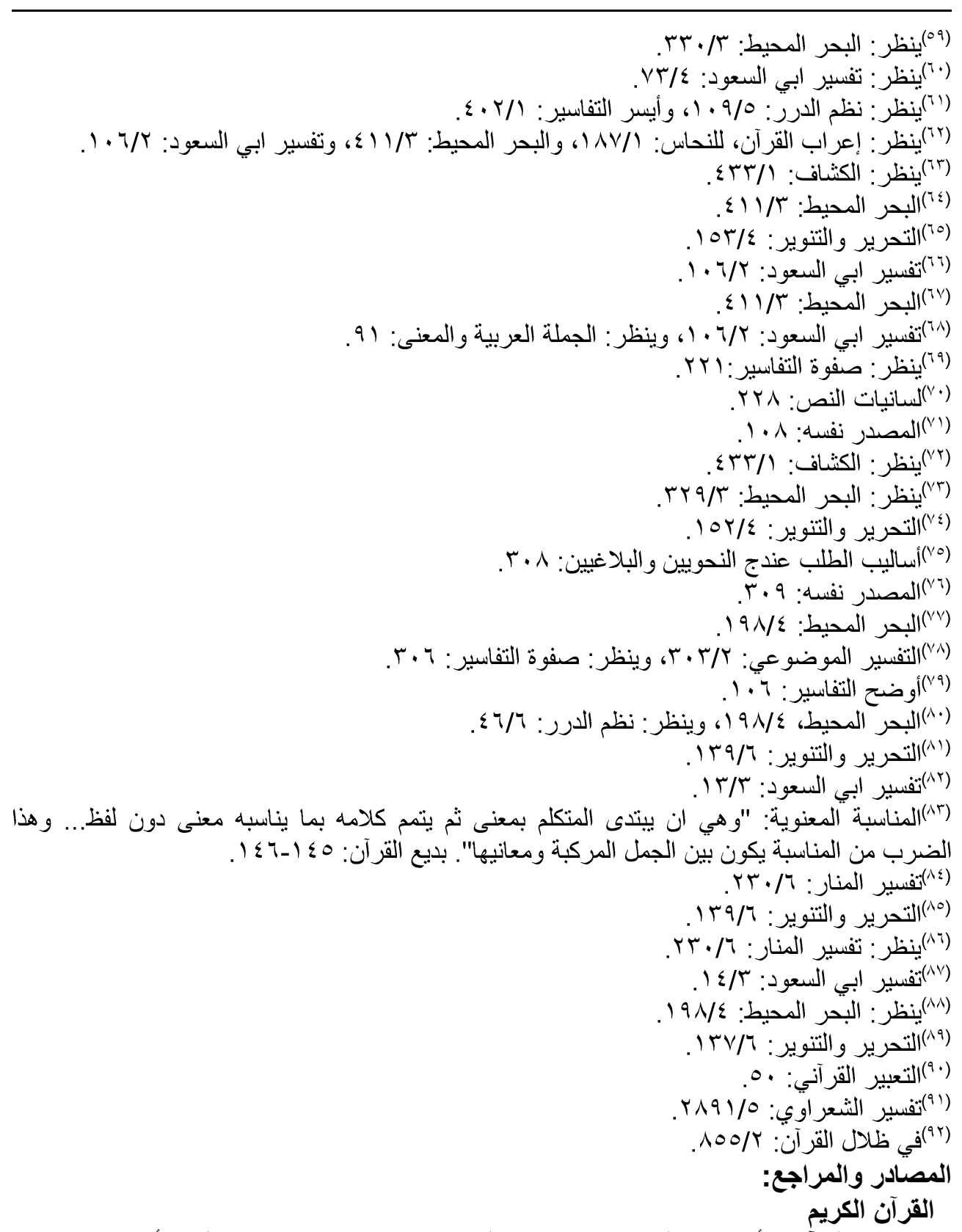

'. إعجاز القرآن، لأبي بكر الباقلاني محمد بن الطيب (ت: ب. بـهـ)، تحقيق: السيد أحمد صقر، دار

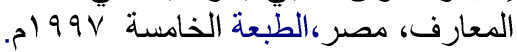

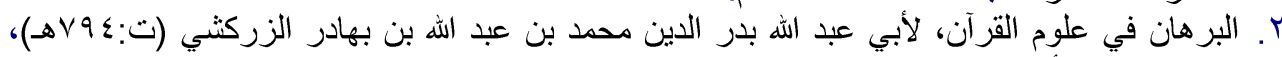

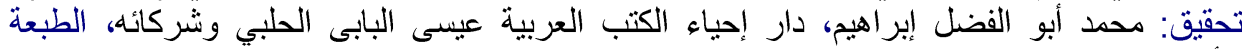

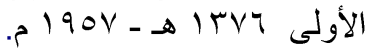
r. إعراب القزآن وبيانه، لمحيي الدين بن أحمد مصطفى درويش (ت: ب.ـ؛ (هـ)، دار اليمامة، دمثق،

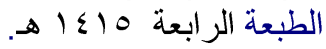

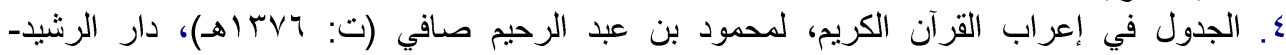

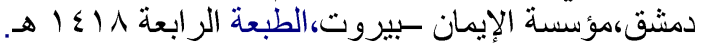


ه. . الجنى الداني في حروف المعاني، لأبي محمد بدر الدين حسن بن قاسم بن عبد الله بن عليّ المرادي (ت:

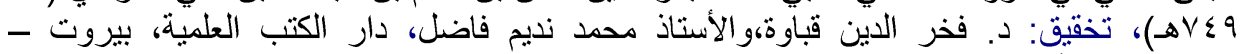

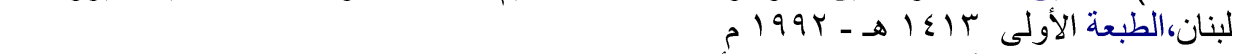

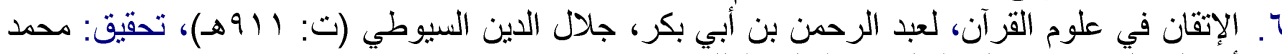

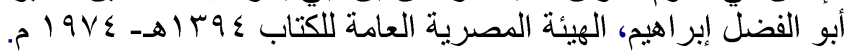

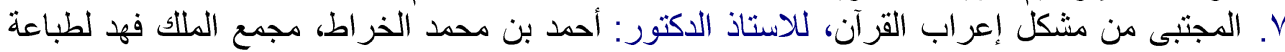

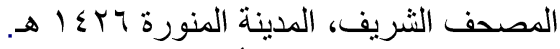

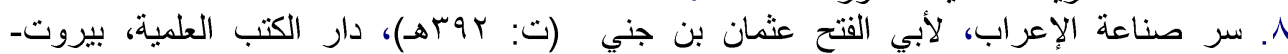

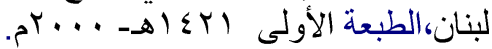

9. التفسير القر آني للقرآن، لعبد الكريم يونس الخطيب (المتوفى: بعد • qجاهـ)، دار الفكر العربي، القاهرة

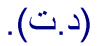

• . . (الصفوة التفاسير، لمحمد علي الصابوني، دار الصابوني للطباعة والنشر والتوزيع، القاهرة، الطبعة

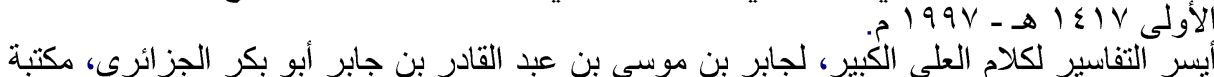

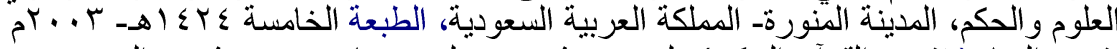

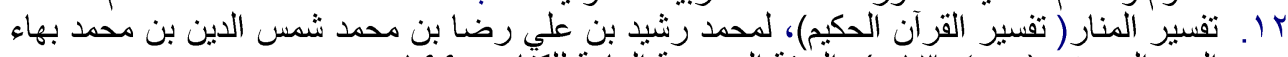

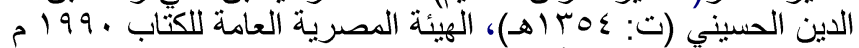

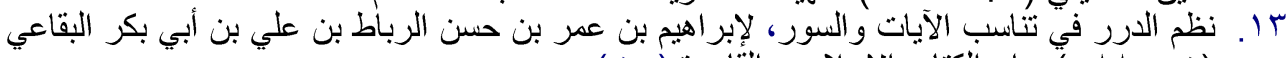

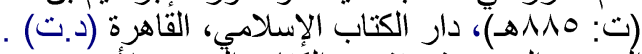

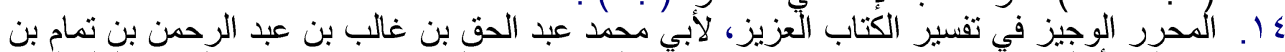

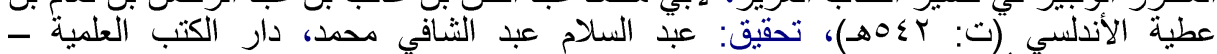

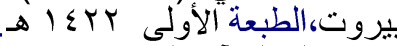

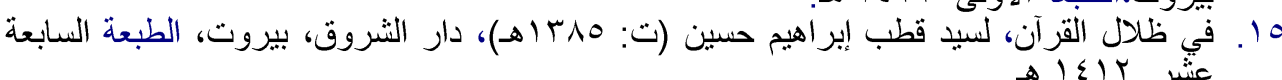

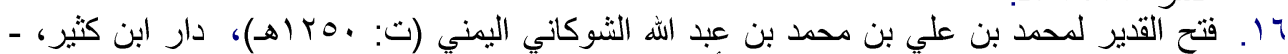

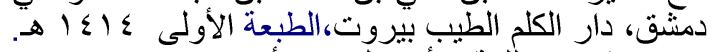

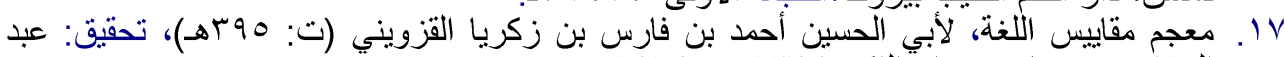

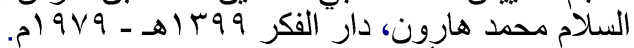

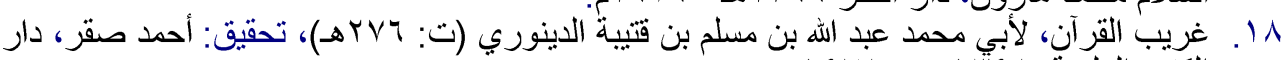

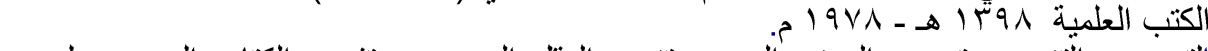

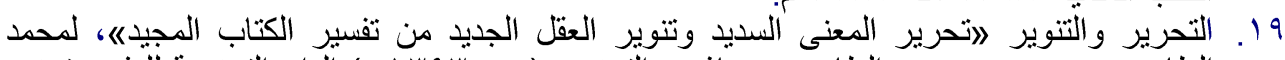

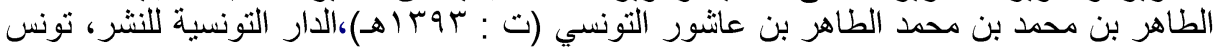

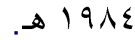

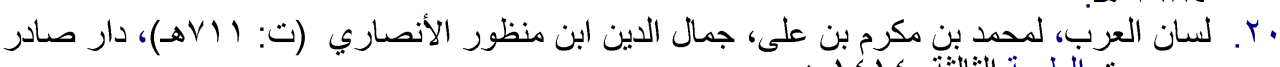

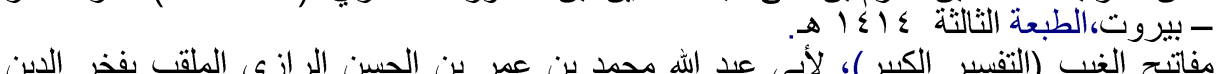
آr. مفاتيح الغيب (التفسير الكبير)، لأبي عبد اله محمد بن عمر بن الحسن الرازي الملقب بفذر الدين

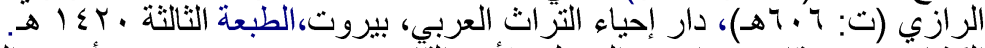

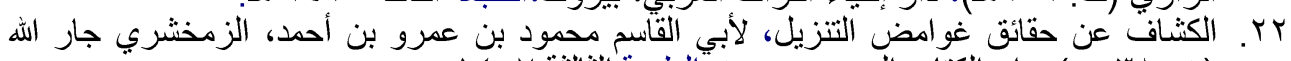

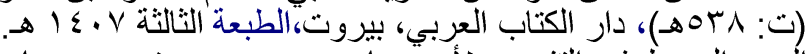

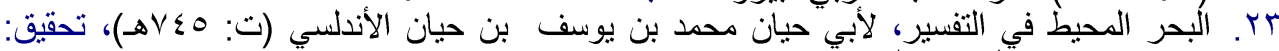

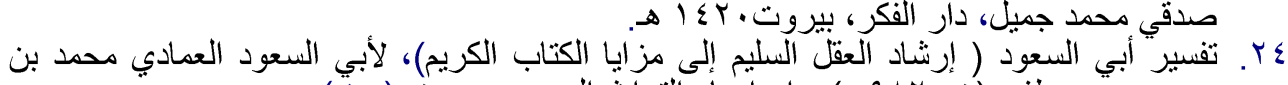

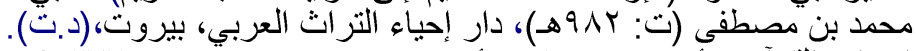

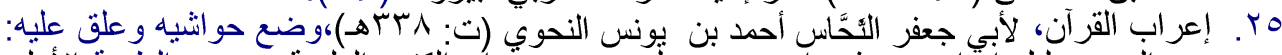

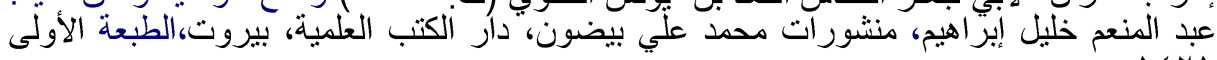

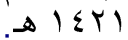

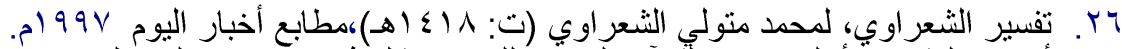

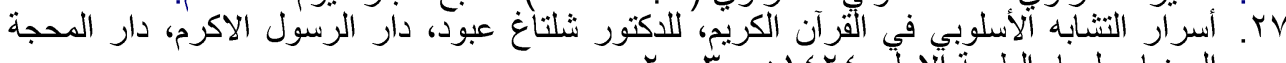

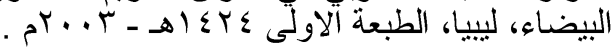


^^r. النظم القر آني في تفسير نظم الدرر في تتاسب الآيات والسور، للأكتور : عقبد خالد حمودي العزاوي،

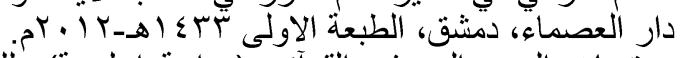

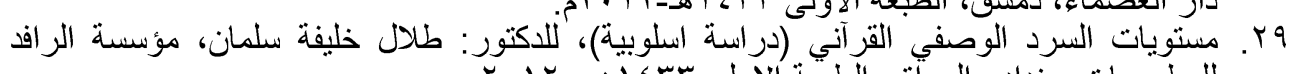

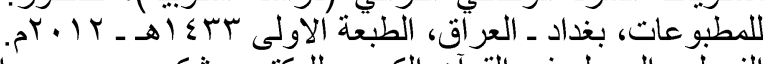

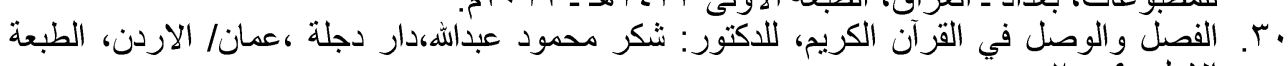

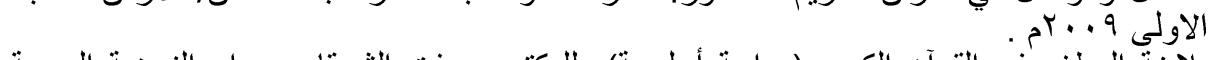
ابr. بلاغة العطف في القرآن الكريم (دراسة أسلوبية)، للاكتور : عفت الثرقاوي، دار النهضة العربية،

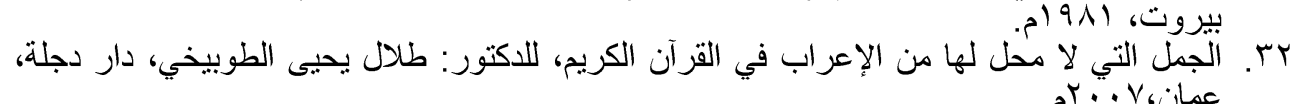

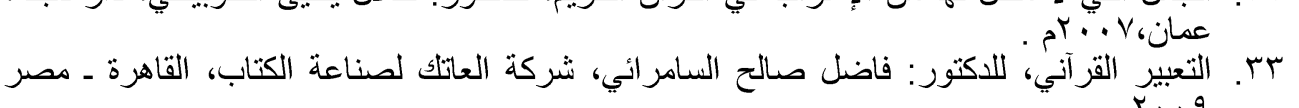

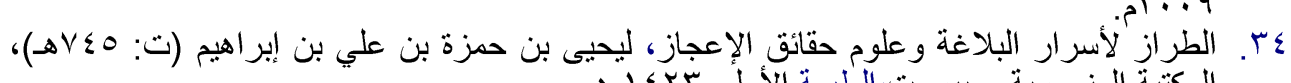

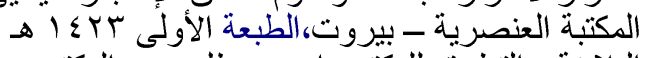

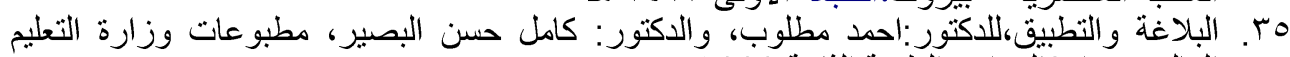

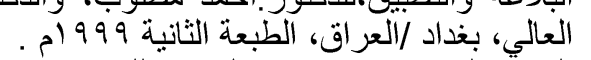

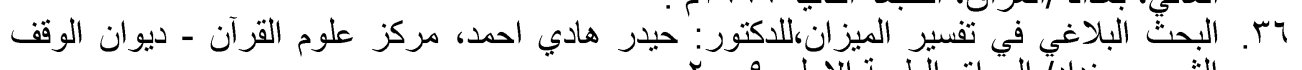

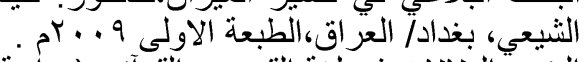

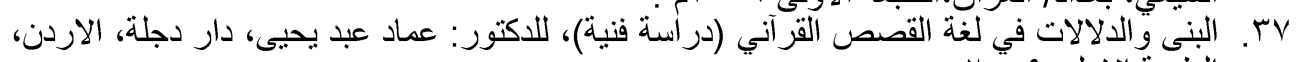

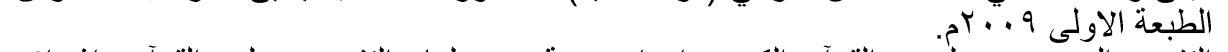

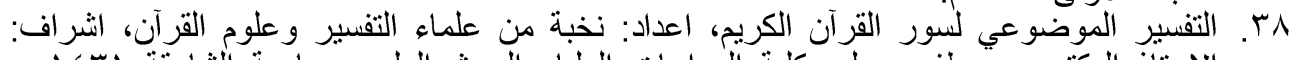

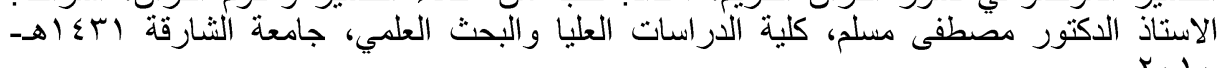
. 1 . 1 .

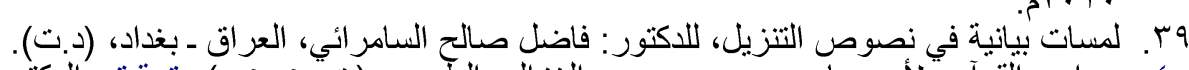

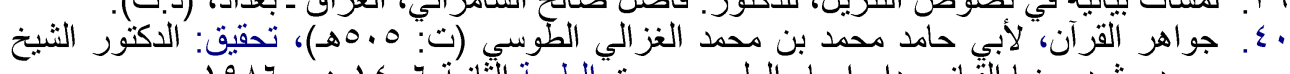

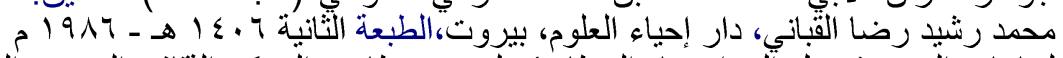

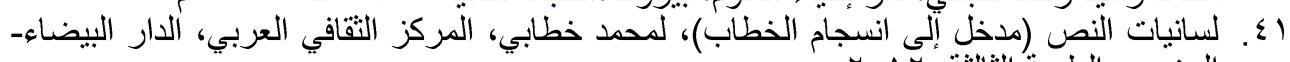

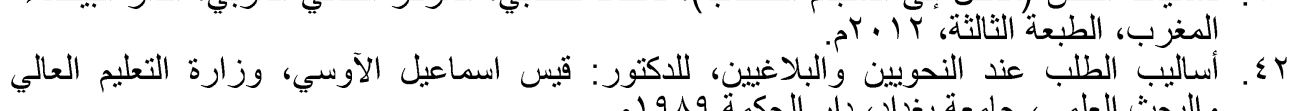

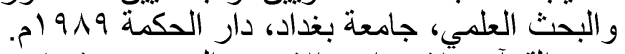

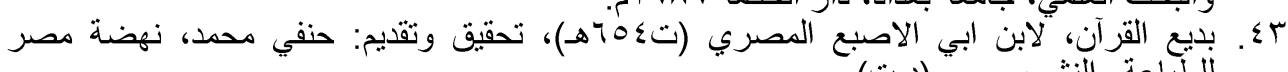

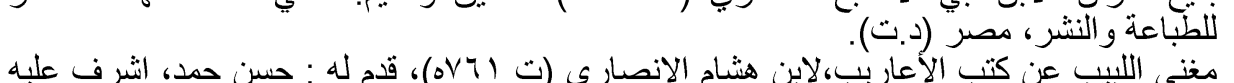

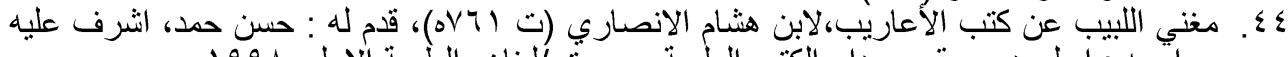

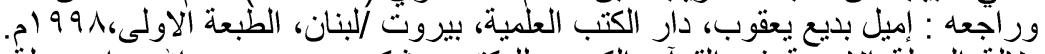

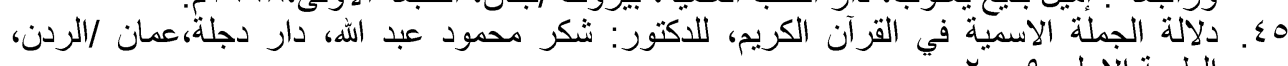

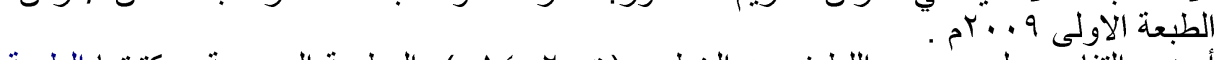

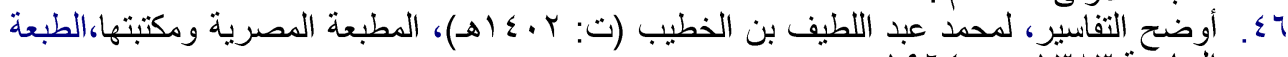

